\title{
A Review on Suspension Thermal Spray Patented Technology Evolution
}

\author{
Maniya Aghasibeig ${ }^{1} \cdot$ Fariba Tarasi $^{2} \cdot$ Rogerio S. Lima $^{1} \cdot$ Ali Dolatabadi $^{2} \cdot$ \\ Christian Moreau ${ }^{2}$
}

Submitted: 4 April 2019/in revised form: 5 August 2019/Published online: 22 August 2019

(C) ASM International 2019

\begin{abstract}
Since the introduction of suspension thermal spray (STS) in 1997, the rapid evolution of this technology has resulted in a critical number of inventions justifying a comprehensive review. Today STS is one of the most important research and development topics in thermal spray. Due to the efforts of different industries, universities, and governmental institutions, STS has reached a certain maturity for implementation in different applications. STS includes any thermal spray process that is based on injection of a suspension of solid particles in a liquid carrier into the gas jet, such as suspension plasma spray, suspension high-velocity oxy-fuel, and high-velocity suspension flame spray. This review is on the state of the art of the STS technology and includes an overview of the current patent situation including the number of patents published in English language, patenting institutions and invention domains. Apparatus and methods, feedstock, and new material systems and applications were identified as the three main domains of focus for the STS inventions. The presented patents show a general perspective of the current situation and present the technology advancements in each domain. It also shows the potential of implementing this technology in new applications based on the needs
\end{abstract}

Christian Moreau

Christian.Moreau@concordia.ca

Maniya Aghasibeig

maniya.aghasibeig@cnrc-nrc.gc.ca

1 National Research Council Canada, 75 de Mortagne Blvd., Boucherville, QC J4B 6Y4, Canada

2 Department of Mechanical, Industrial and Aerospace Engineering, Concordia University, 1455 De Maisonneuve Blvd. W., Montreal, QC H3G 1M8, Canada of thermal spray market through further technology development.

Keywords suspension thermal spray - suspension plasma spray $\cdot$ suspension high-velocity oxy-fuel $\cdot$ high-velocity suspension flame spray

\section{Introduction}

\section{Brief Historical Facts on the Suspension Thermal Spray (STS) Process}

The next generation of thermal barrier coatings (TBCs) for gas turbine engines, high-performance coatings for wear protection, new-designed electrode/electrolytic components for solid oxide fuel cells (SOFCs), enhanced biocompatible coating structures for implants, superhydrophobic coatings for aircraft wings and wind turbine blades are some of the major applications that urge research on suspension thermal spray (STS) process. Possibilities of technological evolution are immense. Nonetheless, it is interesting to understand how it all started.

The thermal spraying of suspensions and liquid precursors has demonstrated a huge driving force for growth since their inceptions. The first sets of information in the "standard open literature" (i.e., journals, conference proceedings, and patents) showing that liquid carrier feedstocks that could actually be thermally sprayed became available in 1997, i.e., approximately two decades ago. These were pioneer studies led by the University of Sherbrooke (Canada) on suspension spraying (Ref 1) and Stony Brook University (USA) on liquid precursor spraying (Ref 2). After knowing that the thermal spraying of fine particles 
$(<5 \mu \mathrm{m})$ via liquid carriers was possible, from the year $\sim 2000$ to 2005, other laboratories began to perform R\&D on suspension spraying, e.g., the University of Limoges (France) (Ref 3), the National Research Council of Canada (Canada) (Ref 4), and the Research Centre Jülich (Germany) (Ref 5). Liquid-precursor thermal spraying started to be pursued by the University of Connecticut (USA) during the same period (Ref 6). At this time, the plasma spraying of suspensions became known as suspension plasma spray (SPS), whereas the plasma spraying of liquid precursors became known as solution precursor plasma spray (SPPS). In this manuscript, the expression STS refers to suspensions sprayed via different thermal spray techniques, e.g., plasma spray and HVOF.

Specifically regarding STS, at that time the researchers/ engineers did not know (1) what "functional" torch/injector/spray parameters to use, (2) how to make "reliable" suspensions and (3) how to feed the suspensions into thermal spray torches. In other words, the technology was "improvised" and troubleshooting was common. In 2015 (i.e., about 10 years later), the (1) first sets of torch/injector/spray parameters were identified, (2) commercial suspensions started to become available in the market, as well as (3) the first generation of commercial suspension feeders for STS was produced. This was the beginning of the industrialization of STS.

Today STS is one of the most important R\&D venues in thermal spray processing and now it is an industrial process. Many research centers, universities, and industries all over the world are expending a considerable amount of resources in the technology. Moreover, the number of graduate students and postdocs working on STS is on the rise. In addition, to better understand why STS is a revolution in thermal spray and why STS differs so much from traditional thermal spray coating processing, it is necessary to highlight the major differences between both techniques.

\section{Traditional Thermal Spraying of Powder Feedstocks}

In traditional thermal spray processing the feedstock material can be categorized in one of these three formats: (1) a powder, (2) a metallic wire, or (3) a ceramic rod. Although metallic wires and ceramic rods played an important contribution in the thermal spray market up to the 1970s, the huge majority of feedstock materials for thermal spraying today are found in powder form. This is highly related to (1) the introduction of TBCs produced via air plasma spray (APS) as a regular product for gas turbine engines (1980s), as well as (2) the advent of high-velocity oxygen fuel (HVOF) WC-based coatings for landing gears and wear and corrosion industries (1990s). These applications are (1) among the most important ones in the thermal spray market in the twenty-first century and (2) require powder feedstock particles.

As a "rule of thumb," typically the majority of the feedstock powder particles exhibit diameters somewhere within the 5-100 micron scale. Depending on the feedstock material (e.g., ceramic, metal, polymer or composites) and the spraying process (e.g., APS, HVOF and flame spray), the particle size cut is tailored to achieve optimal processing conditions in order to engineer coatings for specific applications. In addition, these powder particles are fed into the spray torches by a carrier gas via a powder feeder.

In the traditional thermal spraying, the fully and/or semi-molten microscopic particles impact the substrate surface or previously deposited layers at or near a $90^{\circ}$ angle. This is due to their high inertia/momentum, i.e., they do not follow the streamlines of the thermal spray jet at or next to the coating/substrate surface, i.e., the streamlines are deviated and move across the coating/substrate surface. At the impact with the substrate surface or previously deposited layers, the particles deform via spreading, solidify, and form the coating microstructure (overlapping of arriving splats). The splats exhibit diameters varying from tens to about a hundred microns and thicknesses ranging from $\sim 1$ to few microns, thereby forming the socalled anisotropic lamellar microstructure.

The coating porosity values typically range from 5 to $20 \%$ for APS and 1 to $5 \%$ for HVOF processing, although denser and more porous coatings can also be produced under controlled conditions for these processes. The minimum coating thickness to uniformly coat a given surface is considered to be $\sim 100$ microns. The majority of the coatings exhibit thickness varying from $\sim 100$ to 500 microns. But the maximum coating thickness can reach few millimeters for some specific applications.

It is important to highlight the fact that particles smaller than $\sim 5$ microns in diameter cannot be properly fed into thermal spray torches via carrier gas-based powder feeders. This is mainly related to low flowability and injection difficulties of fine particles. As the particle size decreases, the surface-area-per-volume ratio of the powder increases. The higher this ratio, the higher the contact and friction among particles, i.e., their flowability is drastically reduced and they start to clog the hoses and tubing of the equipment. In addition, smaller particles cannot be injected into the core of the flame due to their lower mass. If a higher carrier gas flow rate is used, it will cause interference with the flame. Therefore, traditional powder thermal spraying is typically limited to $\sim 5$-micron particles at the lower end of the particle size cut. 


\section{Overview of STS Process}

STS is a thermal spray technique that also uses powders as the feedstock. However, completely different from traditional thermal spraying of powders, in STS, particles smaller than $\sim 5$ microns are chosen as feedstock material. Some of them can be even found within the nano-to-submicron range. In order to overcome the clogging problems previously described, these fine particles are put in a liquid suspension (i.e., slurry). Fine particles in a slurry exhibit flowability levels higher than those of fine particles in a gas. Typically, alcohol (e.g., ethanol) or water is employed as the liquid medium, in addition to dispersants to avoid particle agglomeration. The use of water versus alcohol as the liquid medium is of interest due to safety issues and cost. Figure 1 shows a schematic view of a suspension thermal plasma spray system with radial injection.

The amount of fine particles suspended in the slurry (i.e., solids concentration) is typically found within 5-50 wt.\%. Lower and higher concentrations are also possible, but they would lead to low deposition efficiency (DE) values $(<5 \mathrm{wt} . \%)$ or potentially suspension injector clogging (> $50 \mathrm{wt} . \%)$. The suspension can be made of a single-phase material or a composite suspension made of two or more materials.

The slurry suspension is pumped into the thermal spray torch via tubing and hoses and injected into the thermal spray jet (e.g., plasma plume or combustion flame), at rather the same or similar position at which powder particles in traditional thermal spray would be fed. The suspension is injected into the thermal spray jet either (1) in the form of atomized droplets or (2) as a liquid stream. Once injected, the atomized droplets or the liquid stream undergo (1) fragmentation (created by shear forces) and (2) evaporation of the liquid phase. After these two steps are completed, the resulting particles inside the thermal spray jet exhibit a combination of submicron up to few microns in size (Ref 7). The resulting particle size in the jet will depend on (1) the particle sizes employed during the suspension fabrication, (2) the characteristics of the suspension itself (e.g., surface tension), and/or (3) the way the suspension is injected (i.e., atomized or liquid stream), among other factors. These particles can be fully molten or semi-molten once they reach the substrate surface. The minimum coating thickness to uniformly coat a given surface is considered to be $\sim 25$ microns; therefore, STS coatings may close the gap between thick films and coatings. The majority of the coatings exhibit thickness varying from $\sim 25$ to 300 microns. The maximum thickness capability for STS coatings is not fully explored yet.

It needs to be pointed out that while the 5-100 range micron-sized particles of traditional thermal spraying exhibit high inertial levels, STS fine particles tend to exhibit low inertial momentum. Consequently, STS fine particles tend to follow the streamlines of the thermal spray jet even when they are at or next to the coating/substrate surface, which can deeply influence the trajectory of the particles toward the impact point with the substrate or previously deposited layers.

The suspensions can be sprayed by adapting slurry feeders to already established thermal spray torches. Therefore, they are generally called suspension plasma spray (SPS), suspension HVOF spraying, and suspension flame spray or some variations of these names. All these three methods yield quite distinct particle temperature (T) and velocity (V) values, even for the same suspension. In addition, due to the small size of these particles, even high-melting-point pure ceramic materials can be easily sprayed via suspension HVOF; which is a major challenge in traditional thermal spraying.

Consequently, the combination of small particle sizes, low inertia/momentum, and distinct particle $T \& V$ values tend to result in coating microstructures that are very different from those of traditional thermal spraying of powder particles. Overall, there are four basic types of STS microstructures: (1) columnar-grown, (2) segmented, (3) dense, and (4) porous.

Columnar-grown STS coatings are produced when the fine particles follow the streamlines of the thermal spray jet at or next to the coating/substrate surface, thereby flowing across it and reaching the surface at a shallow angle. Little asperities on the surface act as seeding points at which the
Fig. 1 Schematic view of a suspension plasma spray system with radial injection

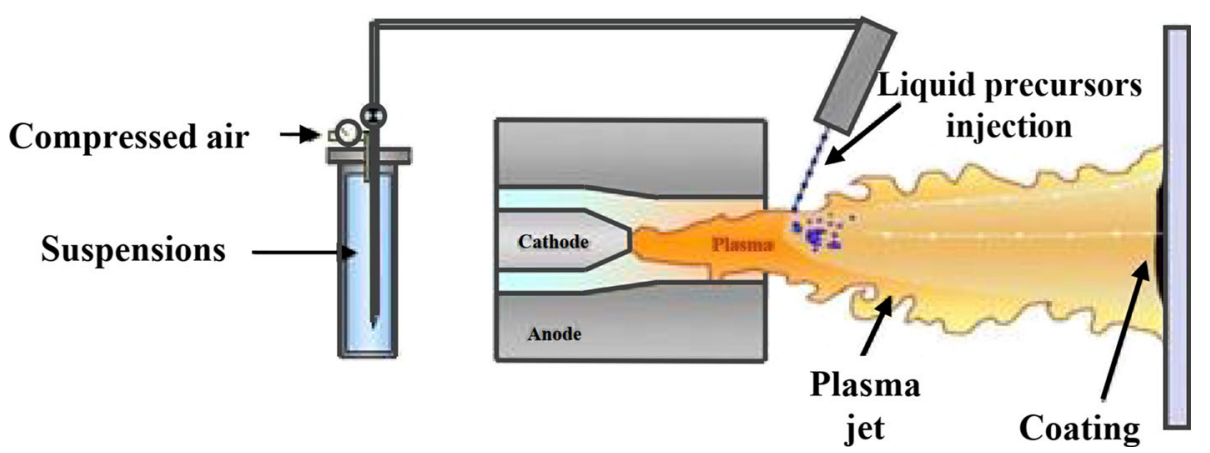


impacting particles attach and start growing/forming individual vertical columns. Vertical cracking is minimized, and porosity bands or gaps are observed in between adjacent columns. This type of microstructure is porous ( $>10 \%$ porosity) and also called "feathery," "arborescent" or "cauliflower."

Segmented STS coatings are formed when the fine particles arrive at the substrate/coating surface at or near a $90^{\circ}$ impact angle. Therefore, they must arrive at the substrate/coating surface at high velocities to have enough inertia/momentum to not follow the thermal spray jet streamlines, i.e., they impact the substrate/coating at a normal angle. The columns are formed by vertical cracking via the release of high tensile stress levels within the coating microstructure (which occurs during spraying). In other words, the vertical cracks define the boundaries in between columns. High coating surface temperatures during spraying need to be generated and high deposition rates are typically necessary to create the stresses required to form the vertical cracks. This type of microstructure is dense $(<10 \%$ porosity) and resembles that of a dense vertically cracked TBC (DVC TBC).

Dense STS coatings are engineered in a similar way as that of the segmented ones, i.e., the fine particles need to arrive at the substrate/coating surface at or near a $90^{\circ}$ impact angle. However, the surface coating temperature and the deposition rates during spraying need to be con- trolled to avoid increasing of the coating tensile stress levels up to the point of coating fracture and vertical cracking formation. The porosity level of this type of microstructure is also $<10 \%$.

Porous STS coatings are engineered in a similar way as that of the columnar-grown ones, i.e., the fine particles need to exhibit a low inertia/momentum to follow the streamlines of the thermal spray jet at or next to the coating/substrate surface. The asperities of the substrate/coating surface will act as seeding points for the particles that impact at shallow angles. These will be the preferential nucleation sites where the coating microstructure will start to build up. But differently from the columnar-grown STS coatings, there are no evident vertically oriented porosity bands or gaps present in the coating microstructure. It is hypothesized that an excess of nucleation sites and/or very low particle momentum/inertia will result in an early and major build-up overlapping. Consequently, no discernible columnar structure is observed. This type of microstructure is typically highly porous ( $>20 \%$ porosity). Examples of each STS microstructure are shown in Fig. 2.

Therefore, the ability to create four distinct types of microstructures, the use of fine particles of single- or multiphase composition and even the capability to combine different processes, opens a myriad of possibilities in terms of STS engineering.
Fig. 2 Examples of STS microstructures: (a) columnargrown, (b) segmented, (c) dense and (d) porous $(\operatorname{Ref} 8,9)$
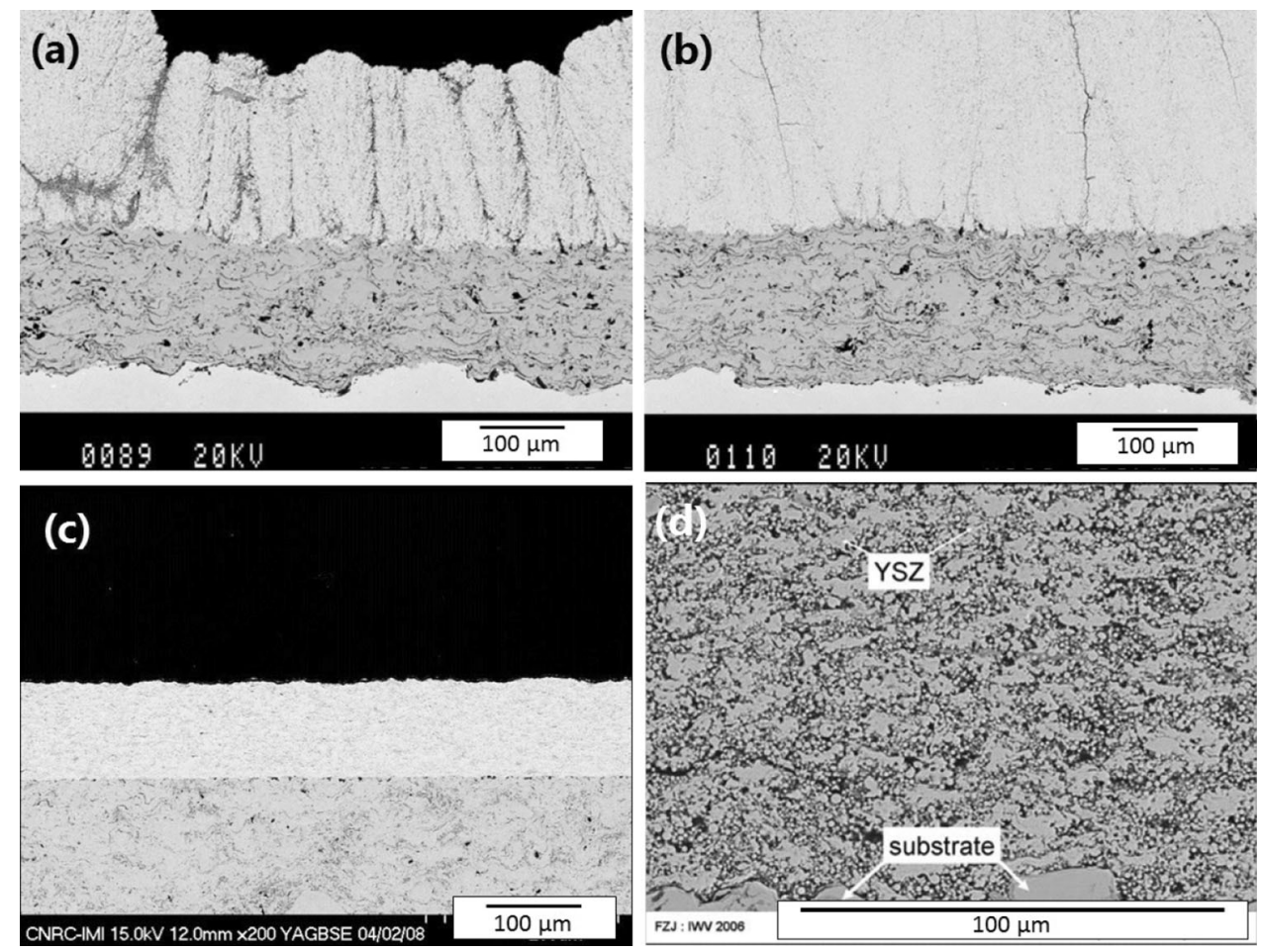


\section{Rational for the Patent Review on STS Processing}

As previously stated, the R\&D activities in research centers, universities, and industries are gaining momentum. It is thought that after 20 years of the introduction of the STS processing in thermal spraying, the number of STS patents has reached a critical value for a comprehensive review. There are a number of literature review papers on the STS process and applications (Ref 10-15). However, as STS is now an industrial process, there is a strong need from the thermal spray community to also know the current state of the patenting situation in STS processing. This is the key objective of this manuscript.b

Initially, this manuscript provides the readers with an overview of the current patent situation, e.g., the number of patents published, patenting institutions and patent domains (subjects). The search methodology is also provided. The technical review of the paper is divided into three sections: (1) Apparatus and Methods, (2) Feedstock \& New Material Systems, and (3) Applications. The Apparatus and Methods section lists some of the main equipment patented to enable STS processing. The Feedstock \& New Material Systems highlights few patented slurry-based feedstocks. The Applications section shows a series of key patent examples on the real-world use of STS technology.

\section{Search Methodology}

This technical IP review includes patents and patent applications on suspension thermal spray (STS) published in English language without any limitations on the country where the patent applications were filed.

Suspension thermal spray designates all thermal spray processes in which a liquid carrier is used for injection of fine solid powder particles into the spray jet to form surface coatings. Using this definition, STS process encompasses suspension plasma spray (SPS), suspension high-velocity oxy-fuel spray (SHVOF), and high-velocity suspension flame spray (HVSFS). The patent search was performed using Questel-Orbit Intelligence software. Orbit Intelligence is a powerful patent search and analysis software with worldwide coverage of more than 100 million patents and 54 million patent families. It includes FullPat and FamPat databases that allow patent search by individual record and invention-based families, respectively (Ref 16). A combination of the following keywords was used for the search: suspension and/or liquid feedstock; thermal and/or flame and/or high velocity and/or plasma; spray and/or coat and/or deposit; SPS. The search returned a total number of 80 findings in English that were published up until January 29,2019 , which is the date that the final search was performed. To avoid duplication, the results contain one patent for each patent family. A patent family includes publication of a patent in multiple countries. For the purpose of completing this review, the authors cited few additional inventions on STS that they were aware of, but were not returned from the search probably due to the selected search criteria.

The patents were then classified into two categories, labeled as exclusive and inclusive. "Exclusive" refers to the patents and patent applications where STS was exclusively used as the coating method for the purpose of the invention, whereas "inclusive" refers to the ones where STS was used as one of the various coating methods as a part of the invention. The patents were also considered as exclusive when SPS with only either atmospheric plasma spray (APS) or solution precursor plasma spray (SPPS) were used as the coating method. When SPS and electronbeam physical vapor deposition (EBPVD) were suggested as the coating technique and the emphasis of the invention was on the microstructure of the coating, the invention was considered as exclusive as well. The following review provides an overview of both inclusive and exclusive categories with focus on the details of the exclusive patents and patent applications.

\section{Patent Evolution and Situation Overview}

As an indicator of the technology evolution, Fig. 3 presents the number of patents and patent applications (both inclusive and exclusive) on STS published as a function of their

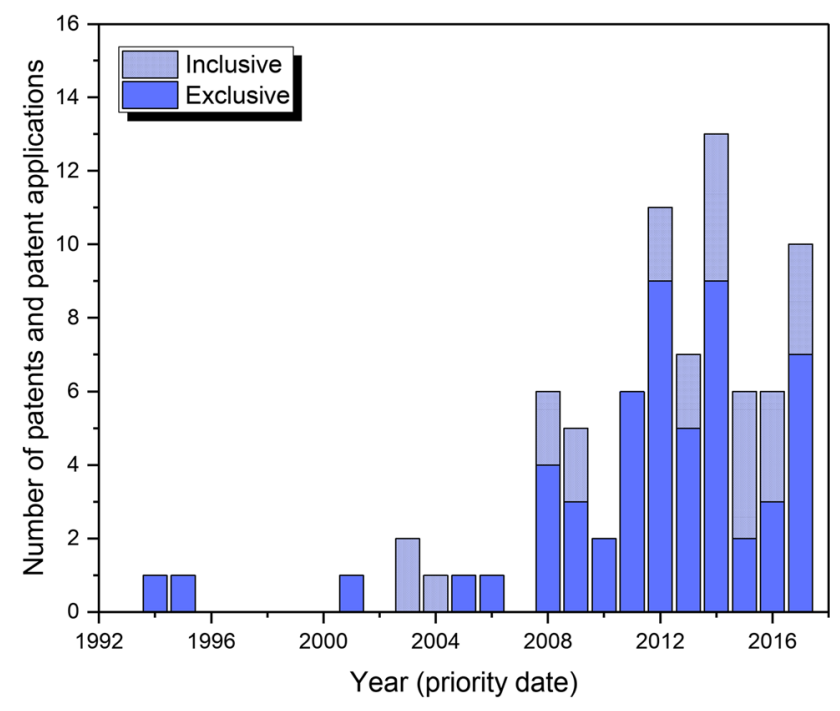

Fig. 3 Number of patents and patent applications inclusive and exclusive to suspension thermal spray as function of priority date (due to the delay of 18 months in between the priority date and publication, the graph partially covers the patent applications for the year 2017) 
Fig. 4 Number of exclusive patents and patent applications issued/published for each original assignee for the period ending in January 2019

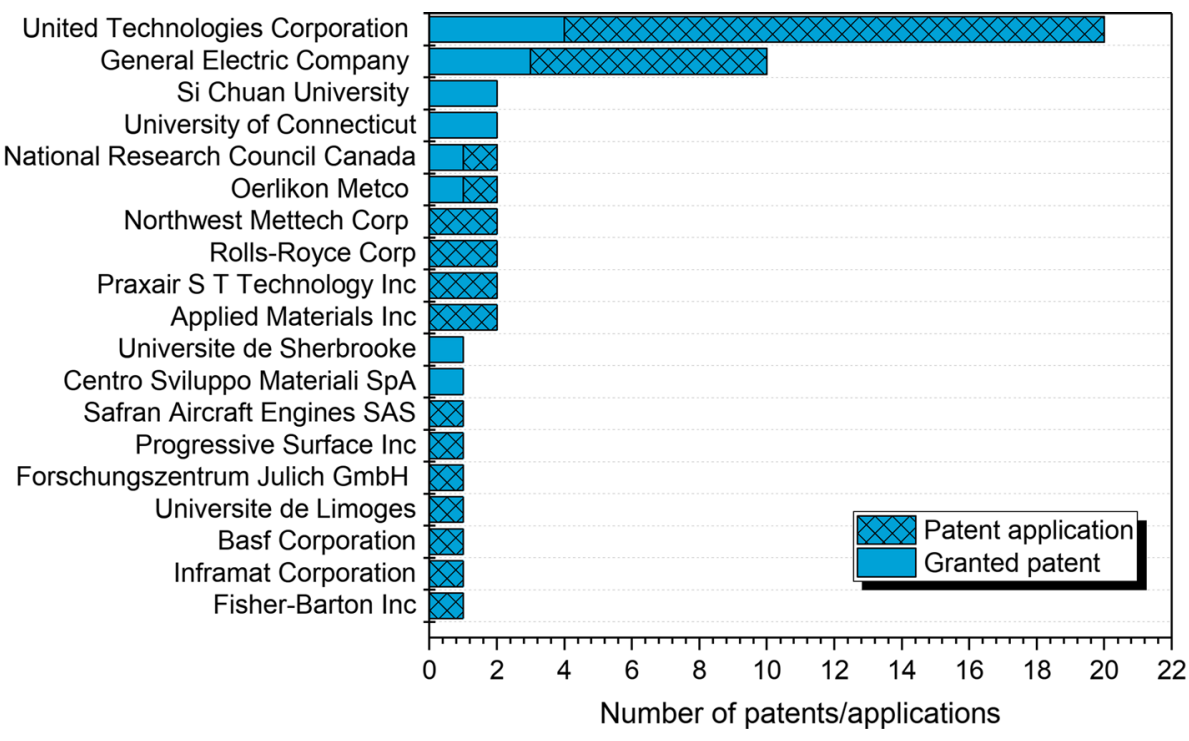

priority date, which is the date of first application filing. It can be seen that of the 80 filed inventions, 55 focus on suspension thermal spray exclusively. The total number of applications is fairly small indicating that the adoption of this technology by the industry is still relatively limited as SPS is an emerging technology. The first patent on suspension plasma spray was filed in 1994 by Gitzhofer et al. (Ref 1) from the University of Sherbrooke. In between 1994 and 2008, only few patent applications were filed on STS. The increasing interest for STS arose from then, when more than three inventions per year were filed with a peak of 13 inventions in 2014. Most of the inventions filed within the period of 2008-2014 were exclusive to STS. It is worth mentioning that the patent applications are published 18 months after the earliest filing date. Therefore, it is expected that the number of inventions to further increase for the year 2017. It also explains why no inventions could be found for the subsequent years (final patent search date: January 29, 2019). Figure 4 shows that 19 original assignees hold a total number of 55 exclusive patents and patent applications related to STS. The main players can be grouped into three categories. Listed in order of number of inventions, these groups are: aerospace industries, powder and system manufacturers and universities and governmental institutions. United Technologies Corporation, from the first group, with 4 patents and 16 patent applications holds the highest number of the inventions on STS, where $65 \%$ of them target SPS-TBCs/-EBCs. This is followed by General Electric Company which holds 10 inventions on STS with $60 \%$ on SPS-TBCs/-EBCs. The high interest in using SPS for development of thermal and/or environmental barrier coatings is depicted in Fig. 5, showing that about $40 \%$ of the inventions have focused on this application. As shown in Fig. 5, the inventions are categorized into 3 main domains and 15 subdomains. The main domains include: (1) Apparatus \& methods, (2) Feedstock \& new materials and (3) Applications. It is noteworthy that this categorization is based on the main area of focus of the invention in the case of overlaps. For instance, if a new material was developed for a certain application (e.g., suspension plasma spraying of a thermal barrier coating), the invention was categorized in the main domain of Applications.

\section{Technical Review}

\section{Apparatus and Methods}

\section{Injection Systems}

Suspension deposition may be performed using a variety of thermal spray systems. However, there has been a limited number of torches used for this application. Although to the knowledge of the authors, the research on some other torches like high-velocity air fuel (HVAF) is ongoing, the ones used in the patents and patent applications to this point are torches employed in flame spray, RF and DC plasma, and HVOF.

As mentioned above, suspension thermal spray was first introduced by Gitzhofer et al. (Ref 1) at University of Sherbrooke, Canada in 1994. The invention was to resolve the feeding issues associated with conventional plasma spray systems that faced major complications when feeding powders finer than 10 microns. In this patent, a method based on feeding a suspension is proposed where the solid particles of the coating material are dispersed in a liquid carrier and injected into a plasma jet, initially, in an RF 
Fig. 5 Categorization of patents and patent applications into 3 main domains and 15 subdomains based on the area of focus

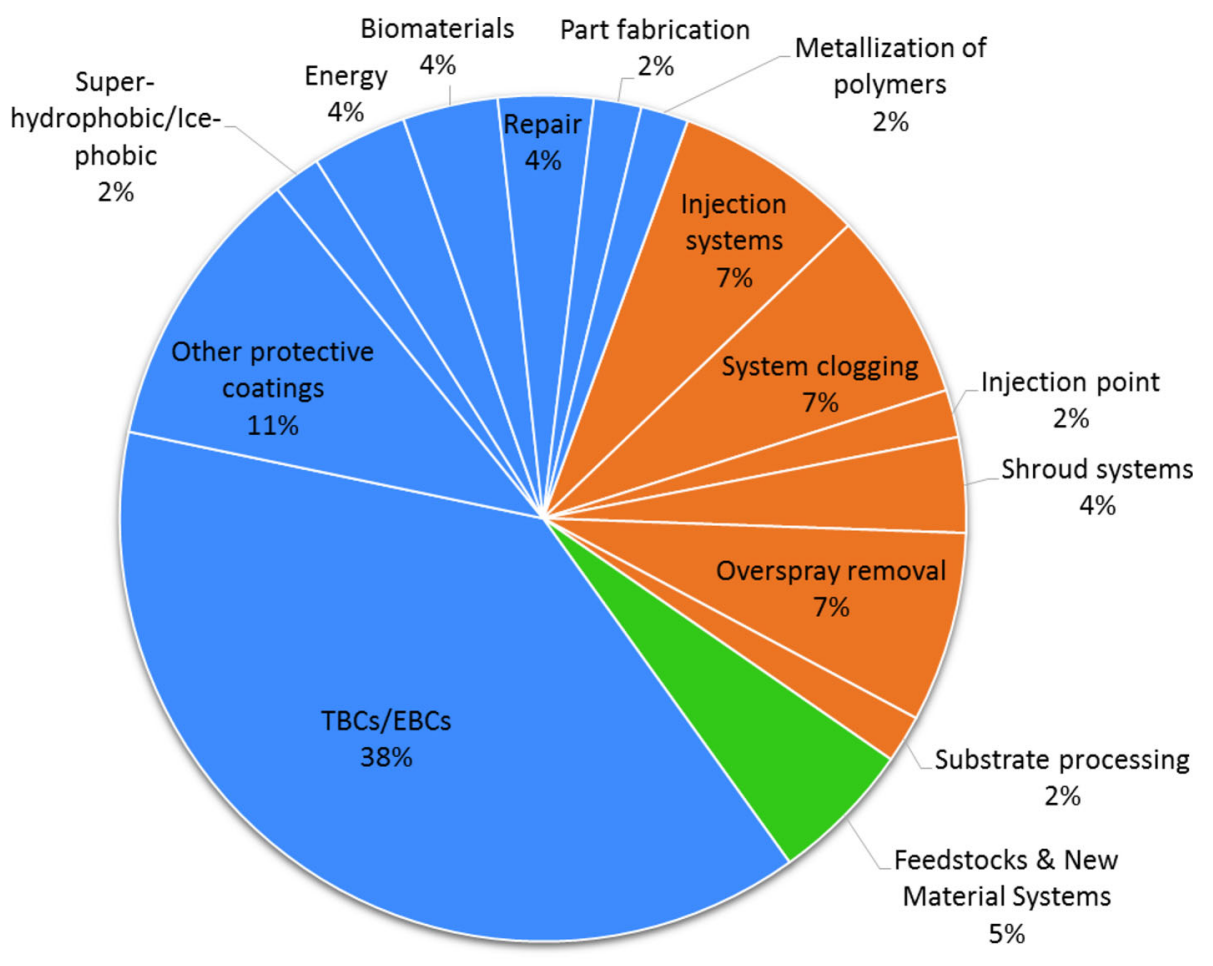

Apparatus \& methods $\quad$ Feedstock \& new materials Applications plasma (Fig. 6). The suspension injection system included a jacketed tube with a conical end. The suspension is injected into the RF plasma torch through an atomizing probe that uses a pressurized gas to shear the suspension and atomizes it into a stream of fine droplets.

Knowing that a large majority of the coatings are deposited using DC plasma torches, using the suspension feed would require some solutions for its effective injection into such torches. When the suspension is injected radially, some issues were raised including the effective heat and momentum transfer from the plasma to the suspension droplets, need for high droplet velocities, and precise injection location and angle with respect to the center of the plasma jet. To address these issues linked to radial injection, axial injection could be greatly advantageous, which was the approach chosen by Oberste-Berghaus et al. (Ref 17). The inventors created a suspension injector assembly to be used in axial injection plasma torches as shown in Fig. 7. This approach can be used with the Axial III Torch (Northwest Mettech Corp., Richmond, BC, Canada) which can generate high gas velocities and plasma temperatures due to high total plasma power (three torches with $50 \mathrm{~kW}$ maximum power each). This way, the limitation of plasma power that could otherwise limit the feed rate is diminished.

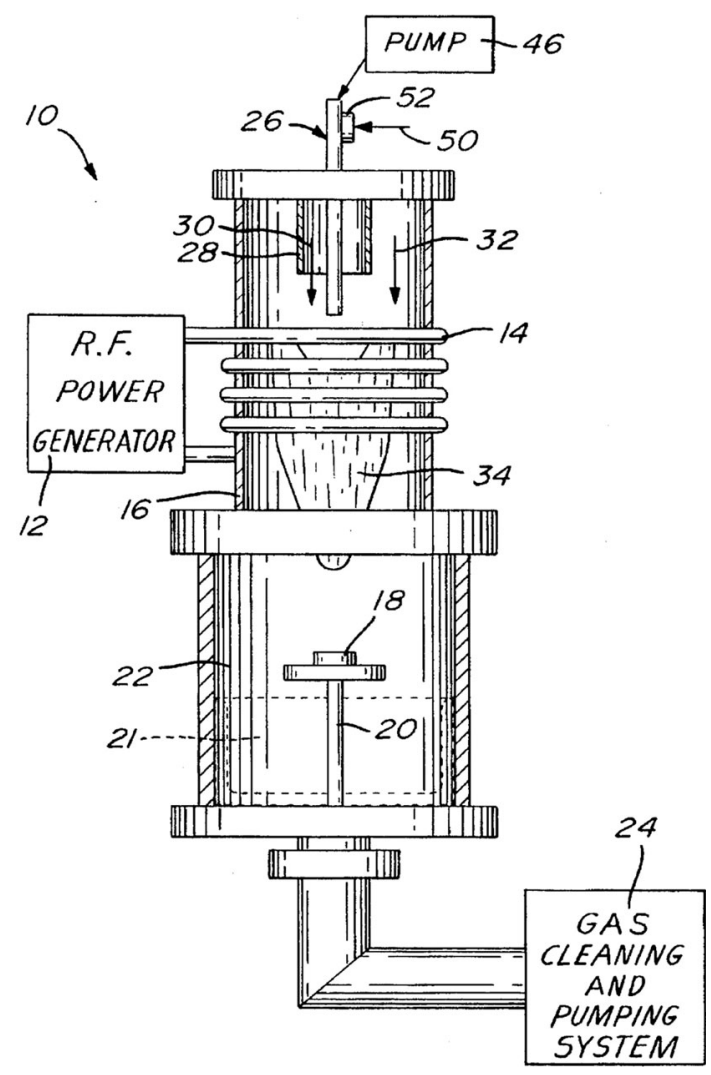

Fig. 6 RF-suspension plasma spray system design (Ref 1) 
The suspension supplied from the suspension vessel/ reservoir, passes through an internal feeding tube, central to the plasma streams. The suspension is propelled into the plasma flame by a propellant gas which is in turn supplied through an internal concentric tube inside the feeding tube (suspension injector assembly) as shown in Fig. 8. This arrangement provides proper and consistent atomization of the suspension and efficient penetration in the three converging plasma jets.

Ma et al. (Ref 18) brought up the idea of making a metallic or cermet coating using a liquid feedstock and injecting the liquid feedstock into a high-velocity oxygen

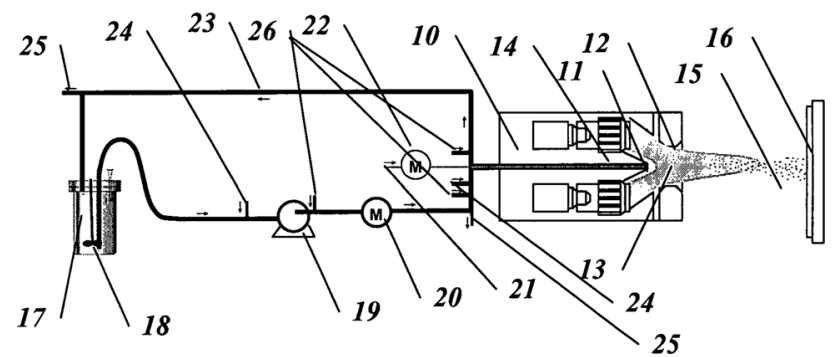

Fig. 7 Schematic side view of converging DC plasma torches (Ref 17)

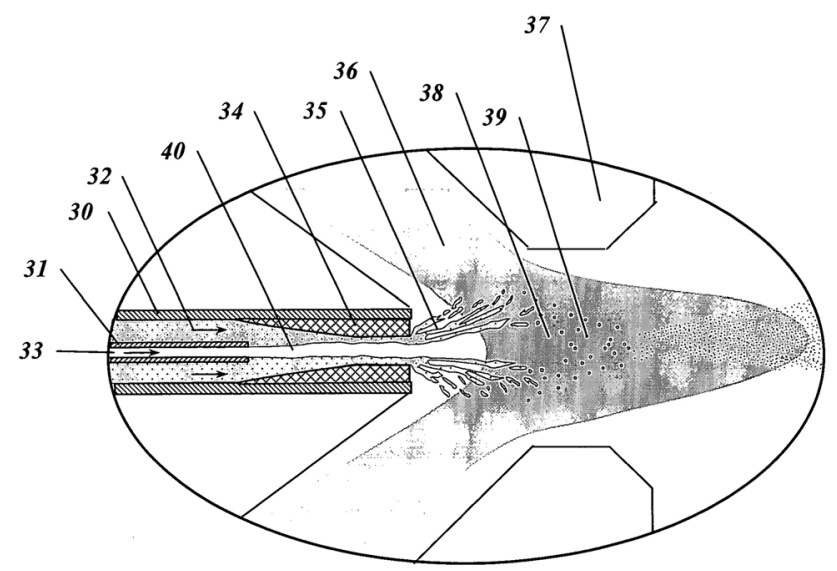

Fig. 8 Schematic design of the suspension feeding tube passing central to the converging torches (Ref 17) fuel flame gun (suspension into HVOF) as presented in Fig. 9. The reservoir is a pressurized tank that uses air or nitrogen pressure to push the suspension toward the combustion chamber of the HVOF gun. In this invention, the use of fine particles through injection was performed to enhance the melting of the particles in the HVOF process in which the heat transfer to the particles is limited due to the lower flame temperature and higher particle velocities. Accordingly, the coatings produced by this method are expected to show relatively high densities, uniform microstructures, high bond strengths, and high deposition efficiencies. The invention suggests several carrier liquids such as water, organic liquids (e.g., ethanol, acetone, glycerol, and kerosene), and solutions comprising inorganic and/or organic metal salt precursors, and combinations of them.

It is worth mentioning that the idea of using a suspension in a HVOF torch opening new applications was also presented by Gadow et al. (Ref 19). However, since the scope of the present review is limited to patents published in English language, this patent is not covered in this review.

Although using a liquid carrier could partially resolve the difficulties associated with the feeding of ultrafine particles, it entails in turn, with some complications. An example is the need of high flow rate of the liquid to accelerate the particles/droplets in a way that they can penetrate the hot gas jet. This results in cooling effect and turbulence in the high-temperature jet. Such phenomena could cause clogging in various sections of the injection system. Consequently, a number of inventions have been proposed to address such adverse effects.

As an advancement in injection systems after the first patent on using an axial plasma torch by Oberste-Berghaus et al. (Ref 17), Burgess et al. (Ref 20) presented another system for the same purpose. Figure 10 shows a schematic view of the front of the torch with the convergent blank and the atomizer geometry. It includes a liquid feedstock delivery system that transports the liquid feed with a controlled flow into the torch core. An automated slurry/precursor feed system was invented based on the same axial injection plasma spray torch using a convergent/divergent
Fig. 9 The setting of the axial injection of the suspension into a HVOF gun (Ref 18)

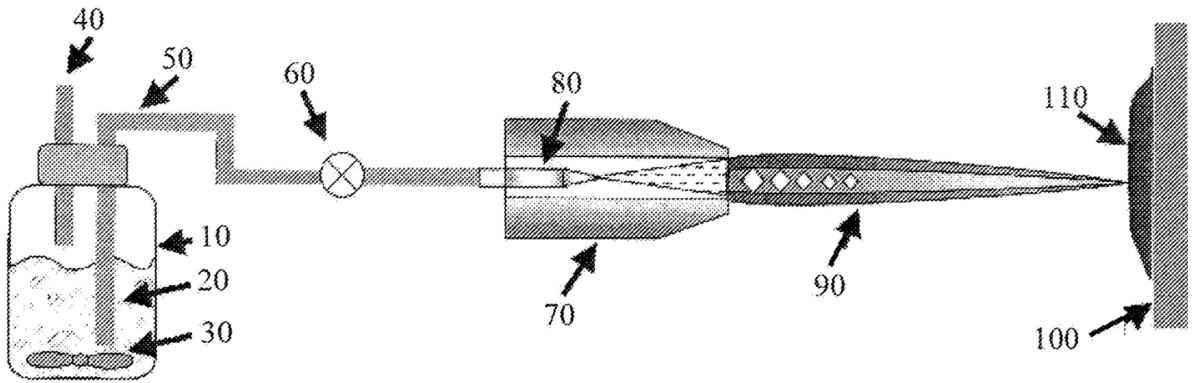


nozzle. Delivering a controlled flow of liquid feedstock into the torch is provided by an electronic controller in combination with a mass flow meter. A Coriolis or ultrasonic mass flow meter is used to maintain constant the suspension flow rate by using a pressure regulator.

\section{System Clogging}

It is known that clogging can diminish the flow of suspension through the injector orifice and can reduce the cooling effect of the feedstock on internal surfaces. This, in turn, can result in temperature rise that boils out the liquid phase and could further generate a very hard crust of agglomerated and sintered powders that would entirely plug the nozzle exit. To avoid this upstream clogging in the injector, efforts were made to keep the injector cool and

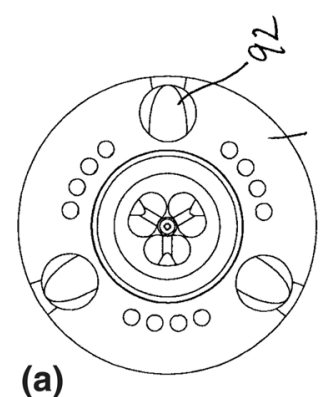

(a)

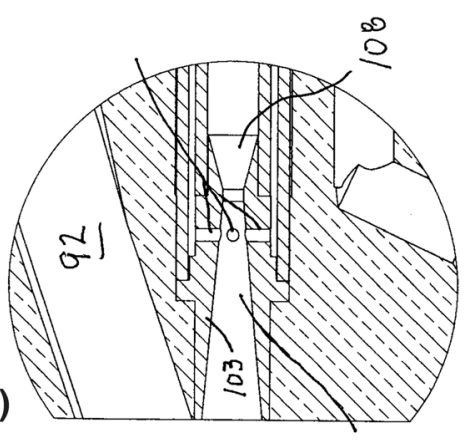

(b)

Fig. 10 The schematics of: (a) front view of a convergence blank illustrating a two-fluid injector, and (b) detail of the cross-section view of the atomizer (Ref 20) clean by switching to gas purge when the liquid feedstock is not fed, especially during plasma gun start-ups and shutdowns. However, although purging the gas kept the injector clean during gas purge, soon after switching back to suspension feed, the injector orifice can be clogged due to the formation of a dried agglomerated crust of solids on the interior surfaces exposed to the cooling gas.

To overcome the above-mentioned problem, Cotler et al. (Ref 21) filed a patent where they designed a cleaning device for the gun as illustrated in Fig. 11. The patent presents a purging system that purges a mist to incorporate a small amount of liquid into a purge gas before its entrance to the feedstock injector. The produced mixture combines the advantages of a high purge gas velocity with high cooling capacity of the mist as well as with the wetting and washing properties of the liquid.

With the aim of minimizing clogging at the injector while reducing the injection pressure in the injection lines, Korolev et al. (Ref 22) disclosed a patent in which they designed a liquid-in-gas injector tube where the diameter of the inner liquid-bearing tube is reduced adjacent the outlet of the injector. The injector atomized the liquid into an Axial III Mettech torch plasma flow. This would not only prevent clogging, but also reduces the pressure required in the liquid feed lines, thus saving energy and increasing lifetime of the peristaltic pump tubing, which reduces maintenance costs. In addition, a smaller volume of the pressure dampener is required to smooth the pressure pulses of the peristaltic pump. As a result, less suspension is wasted in the form of the residues left in the line when the pump is stopped.
Fig. 11 Design summary for the invention: cross section of the system $(\operatorname{Ref} 21)$

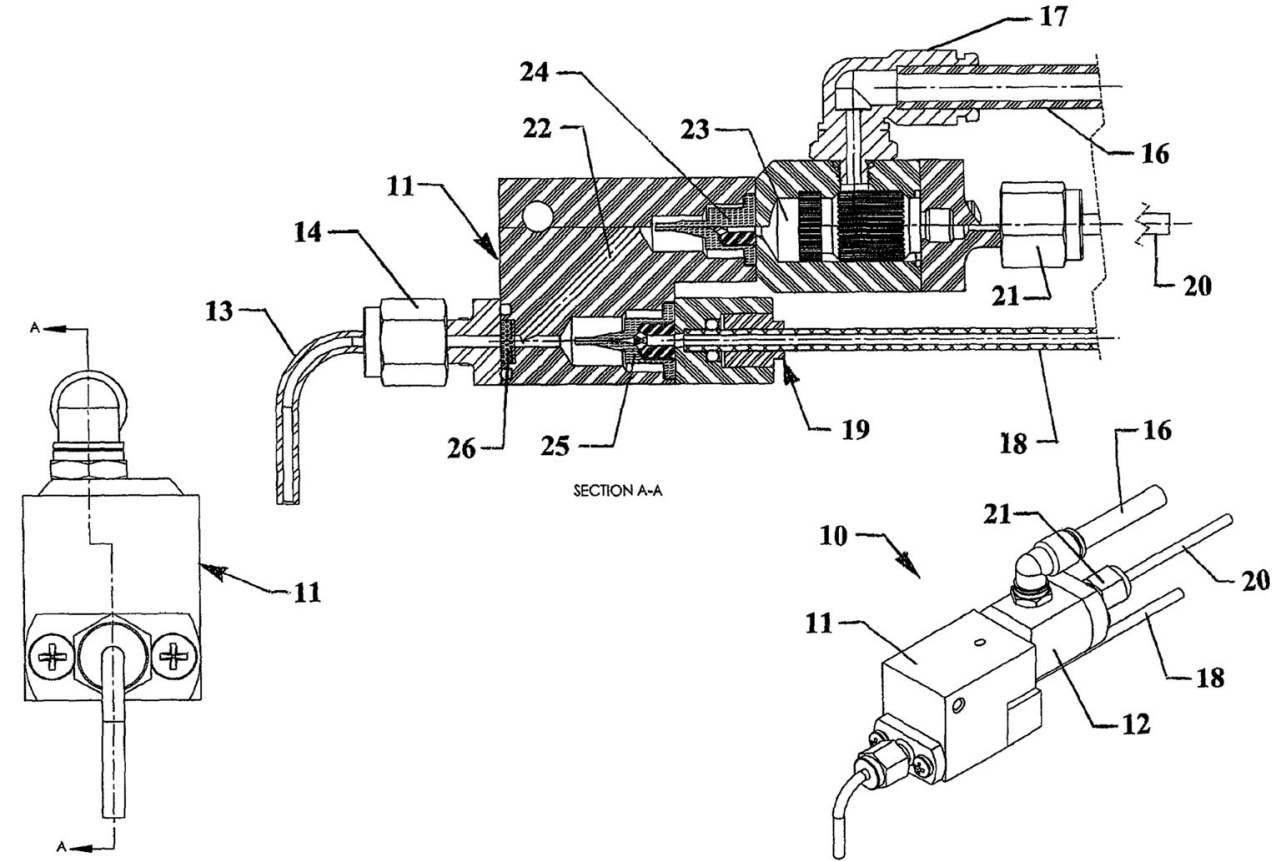


Fig. 12 Liquid injector design to prevent clogging (Ref 22)
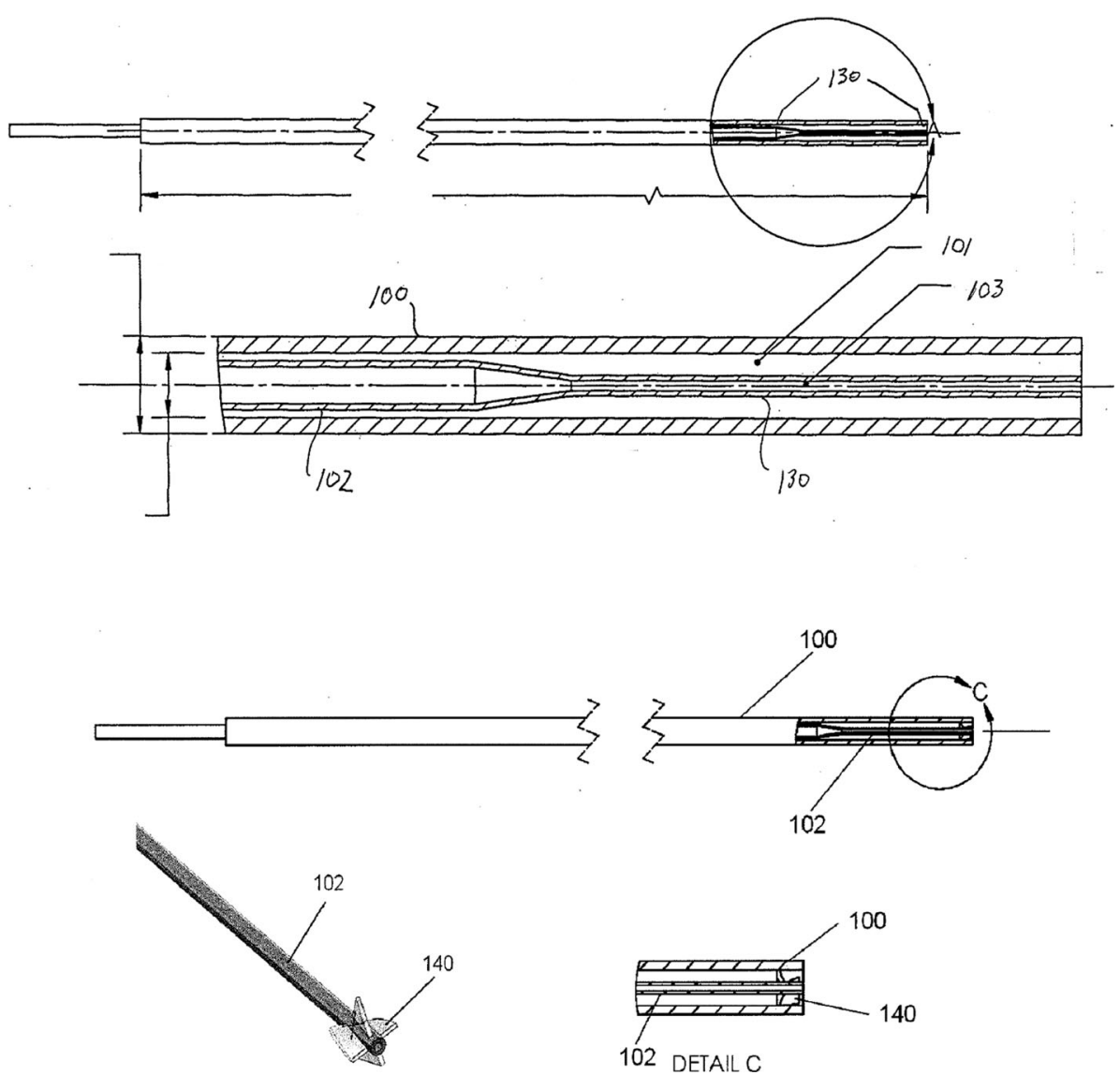

To further reduce the chances of clogging, adding vanes to the outer surface of the inner liquid-bearing tube within the gas-transmitting tube was suggested. It was to impart swirling and to focus the flow of the gas at the exit of the injector tube (see Fig. 12).

Werkheiser et al. (Ref 23) invented a suspension plasma spray feeder apparatus for delivering the suspension. The invention includes the means for "reducing/limiting/relieving" suspension clogging in the system. It involves a vibrator to vibrate the suspension line to avoid formation of solid plugs. In addition, they used filters along the feeding line to eliminate the large agglomerates. It embraces as well, the system for recirculation of the suspension during both short- and long-term pauses of the plasma spray system using multiple valves and $\mathrm{Y}$-shape connections. The design also applies a purge system with sequential introduction of a purge liquid (e.g., water or water-based solution) for cleaning, and a purge gas (e.g., air) for drying the flow path.

In another patent application, the authors proposed the design of a suspension injector system to prevent clogging or obstructing the injector (Ref 24). The injector system can be used with several different thermal spraying systems, such as plasma spray, flame spray, or HVOF. It consists of a circulation loop and a liquid flush. The circulation loop includes a reservoir for storing the coating fluid and a pump or gas pressure source for pumping the coating fluid through a circulation loop conduit and toward the spray torch. A three-way valve (with mechanical or pneumatic actuation) connects the circulation loop to the spray system. This way, the fluid can be redirected to the reservoir without being injected in the event of any plugging or for cleaning the conduit and injection system.

\section{Injection Point}

Increasing the deposition rate in SPS by increasing the suspension flow rate at a single injection point can entrain a number of problems such as the perturbation of the plasma jet that becomes detrimental to fragmentation process and not enough enthalpy to melt the high-melting-point materials.

To overcome these problems, multiple injection points in a variety of orientations and angles was proposed by Hazel et al. (Ref 25). The invention includes a configuration in which the injection nozzles are located on a circle centered on the torch axis and normal to it. Figure 13 shows some of the different arrangements of the injection nozzles proposed in this patent. Figure 13(a) shows the prior art and Fig. 13(b) shows the first proposed oppositely 


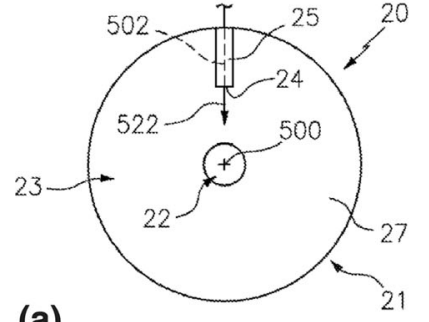

(a)

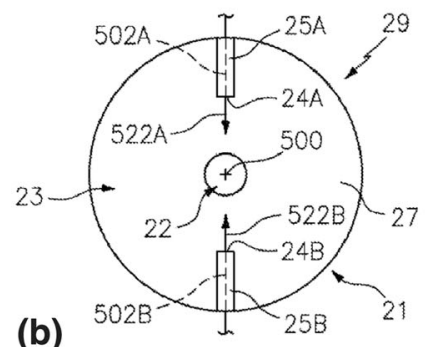

(b)

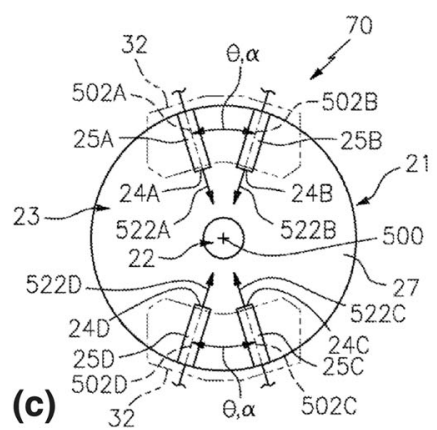

(c)

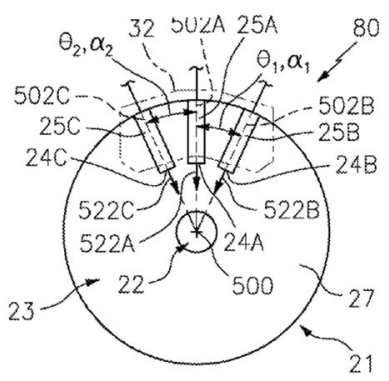

(d)

Fig. 13 Schematic end view of the outlets: (a) and (b) are of a first and second prior art suspension plasma spray guns, (c) and (d) are two of the modified suspension plasma spray guns using low angle and opposing injection axis (Ref 25)

located injection points. Multiple injection points allow using lower liquid momentum (just slightly higher than the plasma plume). Where a reduced angle between the injection axis is recommended as shown in Fig. 13(c) and (d), the technology also brings the advantage of an additive momentum effect for the two liquid flows, thus deeper radial penetration into the plasma. Other solutions for deposition of multiple feeds proposed in this patent are using mixed feeds in the source or reservoir. Also, it is proposed to utilize staggered injection points along the plasma axis.

\section{Shroud Systems}

Increased surface area of the finer particulates in suspension spraying makes them to rapidly heat up and cool down at faster rates than typically larger particles used in standard thermal spray technologies. Accordingly, longer spraying standoff distances required for coating complicated geometries such as turbine blades impose some challenges. As longer standoff distances may cause excessive dwell/ in-flight time, thereby causing cooling and re-solidification of the in-flight particles prior to reaching the substrate. Meanwhile, reducing the standoff distance can cause inadequate heating of the particles such that they are never able to absorb enough heat and properly melt. In both cases, the end result is a lack of coating adhesion to the substrate and reducing of the deposition efficiency. In addition, there are chances of adverse effects on the substrate material due to high heat input from the spray torch that can cause deterioration of the main component in service performance.

To resolve this complication, in two patent applications Petorak et al. (Ref 26, 27) proposed using subsystems for delivering a flow of liquid suspension to the plasma spray systems while being protected by a shroud. The subsystems presented in the two patents have close similarity. The liquid suspension delivery subsystems consist of a nozzle injecting an either inert or reactive gas shroud to the surroundings of the plasma effluent. The inventors also suggested the possibility of using a flame envelope to isolate the injection of the liquid suspension. The shroud or flame envelope was to retain the small submicron-sized particles entrained within the plasma effluent and substantially prevent entrainment of ambient gases into the plasma effluent. The authors likewise presented in their invention engaging a dual gas shield surrounding a suspension plasma spray process toward the same goal. Figure 14(a) and (b) shows the schematics of the prior art and the invented system with a gas shroud, respectively.

Although the presented images are related to axial injection of the suspension liquid, the invention proposes this solution for other injection configurations, i.e., internal and external radial injections. A dual shroud system was also suggested to enable improving heat retention within the region where the droplets/particles flow and fragmentation of the droplets takes place. Dual shroud consists of an inner reactive gas layer and an outer inert gas shield surrounding a suspension plasma spray process.

\section{Overspray Removal}

The coating strength of the thermal spray processes can be improved by reducing the formation and entrapment of suboptimal deposits in the coating. Suboptimal deposits are consisting of either very large particles in conventional spray process that can pass through the torch flow due to their high inertia, or they can be very small particles that do not succeed in entering the high-pressure hot gas flow of the spray jet and/or those that follow the gas flow to the peripheries due to their too low inertia, which are more frequent in suspension spraying processes.

The adverse effects of such suboptimal deposition may be reduced by increasing the fraction of particles in the feedstock that are optimally sized. However, narrowing the particle size range tends to increase significantly the overall cost of the coating process. Alternatively, the entrapment of unwanted suboptimal deposits can be reduced by 

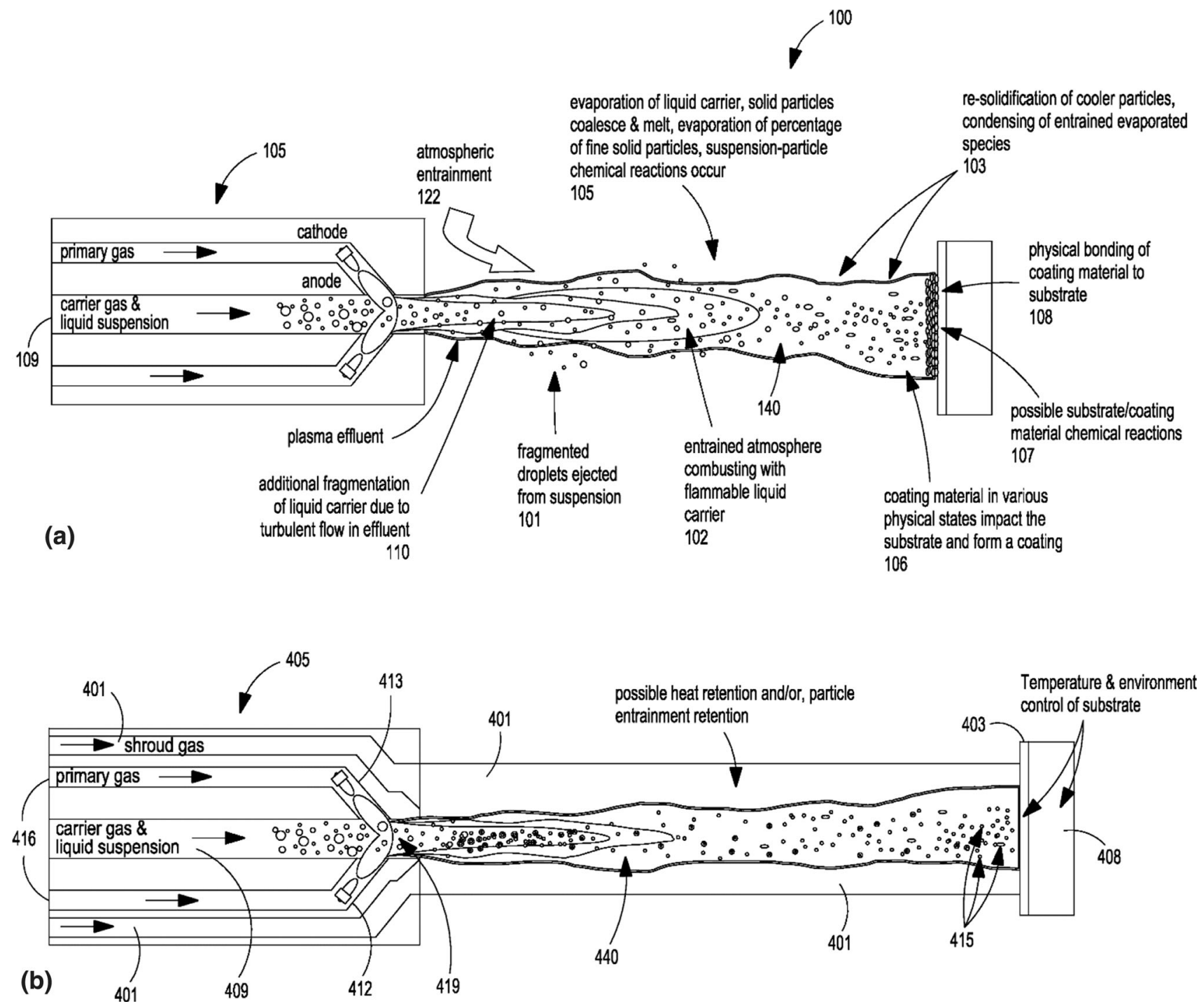

Fig. 14 Schematic illustration of (a) prior art suspension plasma spray process in an axial injection of the liquid suspension and (b) shroud protected system (Ref 26)

cleaning these deposits off the surface between coating passes. An invention by VanEvery (Ref 28) presents such removal of suboptimal deposition using an integrated blasting system. This invention, applicable to both conventional and liquid-based thermal spraying, is appropriate for most of the processes including the combustion-based or plasma spray processes.

The method comprises providing a flow of liquid through one or more injection points surrounding the spray torch (hot gas stream) and projecting the liquid flow onto a spot on the substrate surface where the suboptimal particles deposit, for the goal of eliminating them. Through controlled flow and velocity of the injected liquid, the depth of penetration of the liquid into the gas column is optimized in a way that the liquid can further cool down the particles outside the hot section, prevents them from tightly adhering and provides selectively in situ removal of suboptimal deposits. Figure 15 presents the proposed removal process of the less adhering particles.

A patent application by Mantkowski et al. (Ref 29) discloses removal of the overspray byproduct of the TBC material from the transverse surface portions of the gas turbine component, such as airfoils, when SPS is used for deposition of TBCs. Compressed air and/or abrasive particles (e.g., aluminum oxide) entrained in a gaseous medium is used for the removal process of the overspray byproducts from the second portion of the component after SPS deposition on the first portion of the component, where the first and second portions have transverse surfaces. After the removal of the overspray byproducts, the ceramic coating is then deposited on the second portion of the surface. Figure 16 depicts a typical surface where the sub- 
Fig. 15 Shroud arrangement for eliminating non-optimized particles (\#26 and \#28) and retaining optimally sprayed ones (\#11 or \#24) when the thermal spray system is moving in the direction of arrow \#8 (Ref 28)
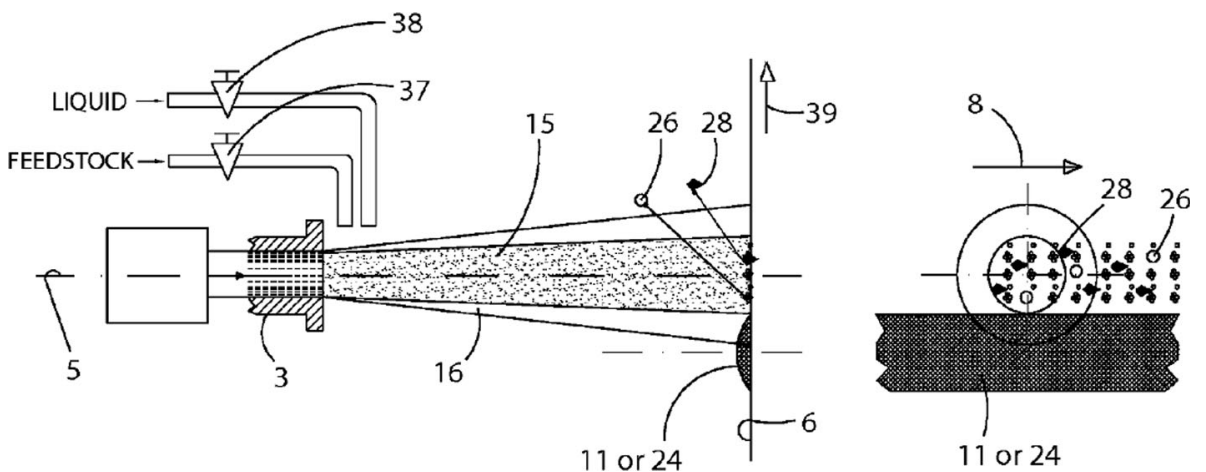

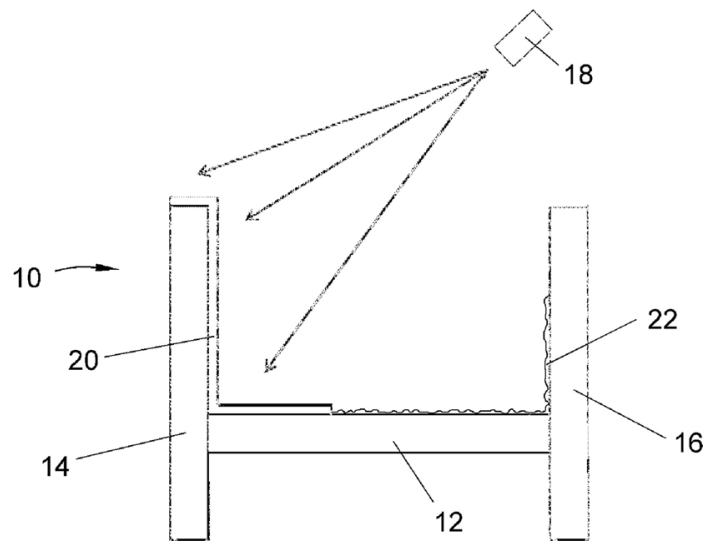

Fig. 16 A typical substrate where some of the surfaces receive suboptimal deposits (\#22) at the shown position of the spray torch (\#18) (Ref 29)

optimally deposited particles may accumulate as compared with the sight of view of the spray gun.

Another approach to eliminate these loosely adhered deposits was proposed by Bochiechio et al. (Ref 30). It involves addition of a nozzle to the plasma torch that injects high-pressure gas (that may also carry a carrier media) to remove the overspray particles from the surface. The gas is injected with a kinetic energy sufficiently high to remove overspray, while being low enough to avoid removal of the well-adhered particles and formed coating. To increase kinetic energy, other applicable media could be either dry ice (carbon dioxide) particles that may sublimate or liquid nitrogen, which may evaporate after removal of the overspray. Liquids like water at its boiling temperature, or polymeric or other low-temperature particulates could be used to provide higher kinetic energy for removal of the overspray material and to evaporate right away. Figure 17 represents the arrangement of the nozzle in regard to the spray torch.

A patent by Hazel et al. (Ref 31) discloses a setup for a plasma spray system with liquid injection comprising a turntable subsystem to position multiple workpieces, a plasma spray subsystem, and an overspray wash

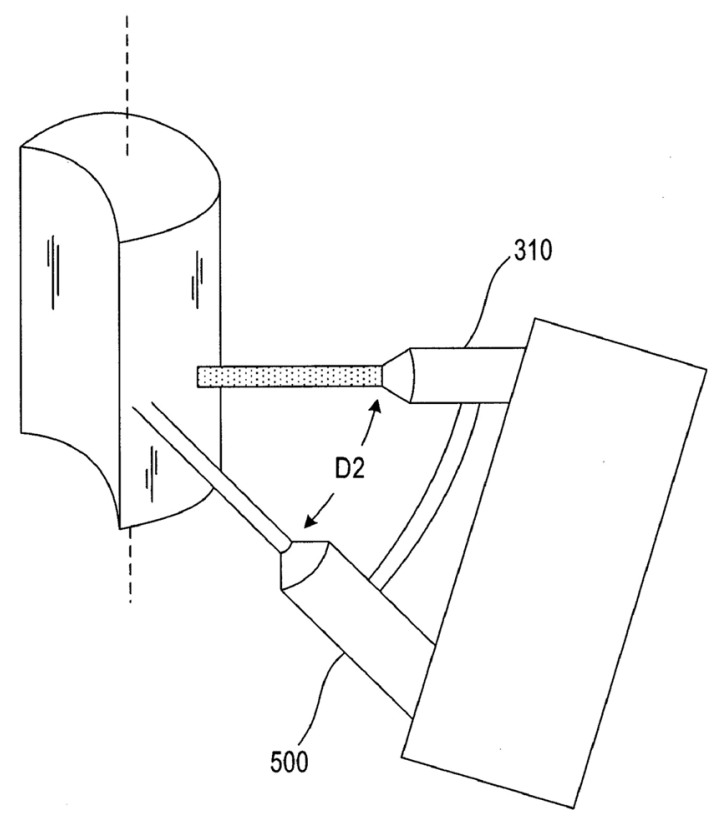

Fig. 17 Schematic of the spray torch $(\# 500)$ and the additional nozzle (\#310) for removal of the overspray deposits (Ref 30)

subsystem. The turntable subsystem rotates multiple workpieces about a central axis, the plasma spray subsystem plasma sprays on the multiple workpieces in a direction transverse to the central axis and the overspray wash subsystem, positioned at 30-330 degrees relative to the plasma spray system, washes multiple workpieces with dry ice. A schematic top view of this setup is shown in Fig. 18.

\section{Substrate Processing}

For the goal of improving adhesion of coatings prepared by thermal spraying, Meillot et al. (Ref 32) proposed deposition of a thin layer up to 150 microns of suspension (or solution precursor) thermal spray as primer layer that can replace the surface preparation for further thermal spray coatings on top of it. To avoid detachment of such primer layer, it is critical to keep the thickness below this 150-micron limit. It is suggested by the authors (though 


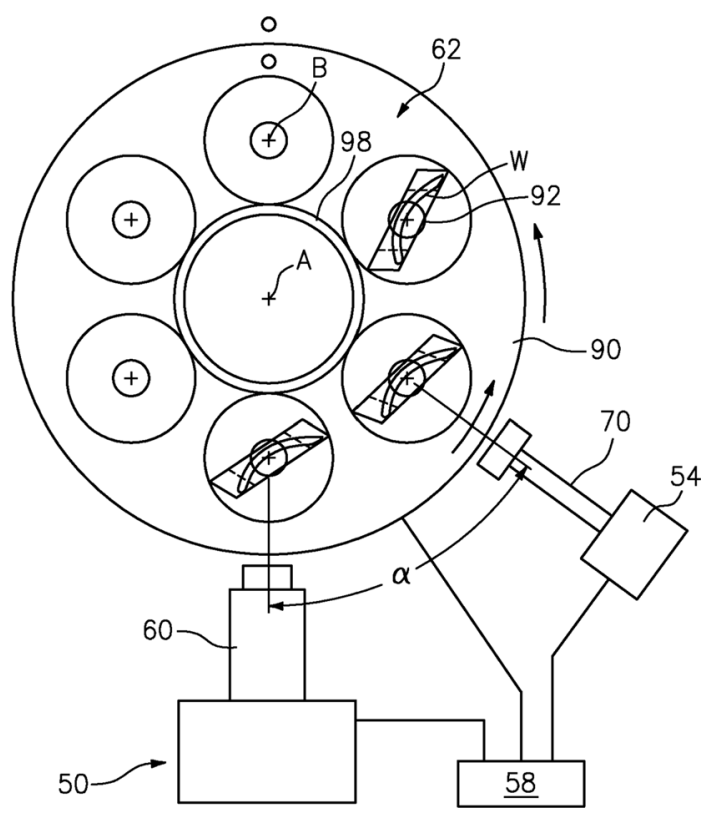

Fig. 18 Schematic top view of a turntable, a plasma spray subsystem (\#50) and an overspray wash subsystem (\#54) (Ref 31)

disputable) that, in this way, new adhesion mechanisms appear such as Van der Waals or electrostatic forces besides the known mechanical anchoring. Such coatings therefore do not require any preliminary surface preparation. The process is considered an appropriate surface preparation for deposition on either metallic or polymeric substrates. It is an effective preparation when the next deposition layer is either of the same composition as the first (/primary) layer, of a crystal structure close to it, and / or possesses a thermomechanical behavior close to that of the first layer.

\section{Feedstocks and New Material Systems}

In spite of the importance of the feed material in terms of liquid formulations or solid powder characteristics, there are only a small number of patents either on feed materials or on new material systems for the suspension technology. This shortcoming is clear especially when compared with technologies for injecting the suspension as well as patents on various applications for this technique. Only two patents were found on solid feed used for suspensions and one patent on using the suspension technology for producing large agglomerated powders from nano-sized particles. No patents were found on suspension formulation. However, it is clear from the existing suspensions offered on the market place that a number of recipes have been developed in industry that are quite successful for targeted applications.

One year after first introduction of the SPS process, in 1995 Strutt et al. (Ref 33) applied for a patent where the suspension feed is proposed for two main purposes. First, for reprocessing the nano-powders generated by RF plasma processing and fabrication of 10-50 micron-sized agglomerates of nanoparticles (powder production). The second application is direct deposition of the same nano-powders for coating production. To do this, the patent recommended using ultrasound for disintegration of the particle agglomerates inside the nanoparticle dispersion in liquid media, in addition to precursor atomization.

A patent that might be considered as new material formulation is disclosed by Jordan et al. (Ref 34). This patent is based on deposition of amorphous metal oxides focusing on various proportions of alumina-yttria-stabilized zirconia (YSZ) compositions. The powder could be fed either in solid form or suspensions of the amorphous powders. This way, a range of compositions rather than a fixed composition could be generated within the coatings.

The most direct approach toward suspension feed production was introduced in a patent application by Callen et al. (Ref 35). They presented this patent based on preformulated dry powders for suspending in the carrier liquid to feed into the suspension thermal spray processes. The powder consists of the right proportion of ingredients which are submicron powders that can be loosely agglomerated and preloaded with dispersing agents via a spray-drying process. It can thus be suspended in the carrier liquid in the solid weight percentage of choice. The invention provides the optimum amount of dispersant for the suspension and is thus self-correcting for any solid loading chosen by the end user (from 5 to $50 \mathrm{wt} . \%$ ). Some of the dispersing agents typically used were polymer salts, inorganic salts, and nonionic organic compounds, etc.

\section{Applications}

\section{Thermal/ Environmental Barrier Coatings}

As indicated in "Patent Evolution and Situation Overview" section, about $40 \%$ of the inventions on STS include patents and patent applications where SPS was used for deposition of barrier coatings for gas turbine engine components. This inclination is mainly related to the advantageous SPS microstructures for improved performance of the TBCs. The SPS microstructures, characterized by formation of columns separated by vertical cracks, are beneficial in TBCs due to their high strain tolerance and high spallation life. Table 1 summarizes the STS coatings used for thermal/environmental barrier coating applications. Thereafter, a review of each invention is provided in this section.

Hybrid and multilayer thermal barrier coating systems have been addressed in several inventions. In these systems, complex TBC layers allow the combined advantages of each individual layer, offering different microstructures 


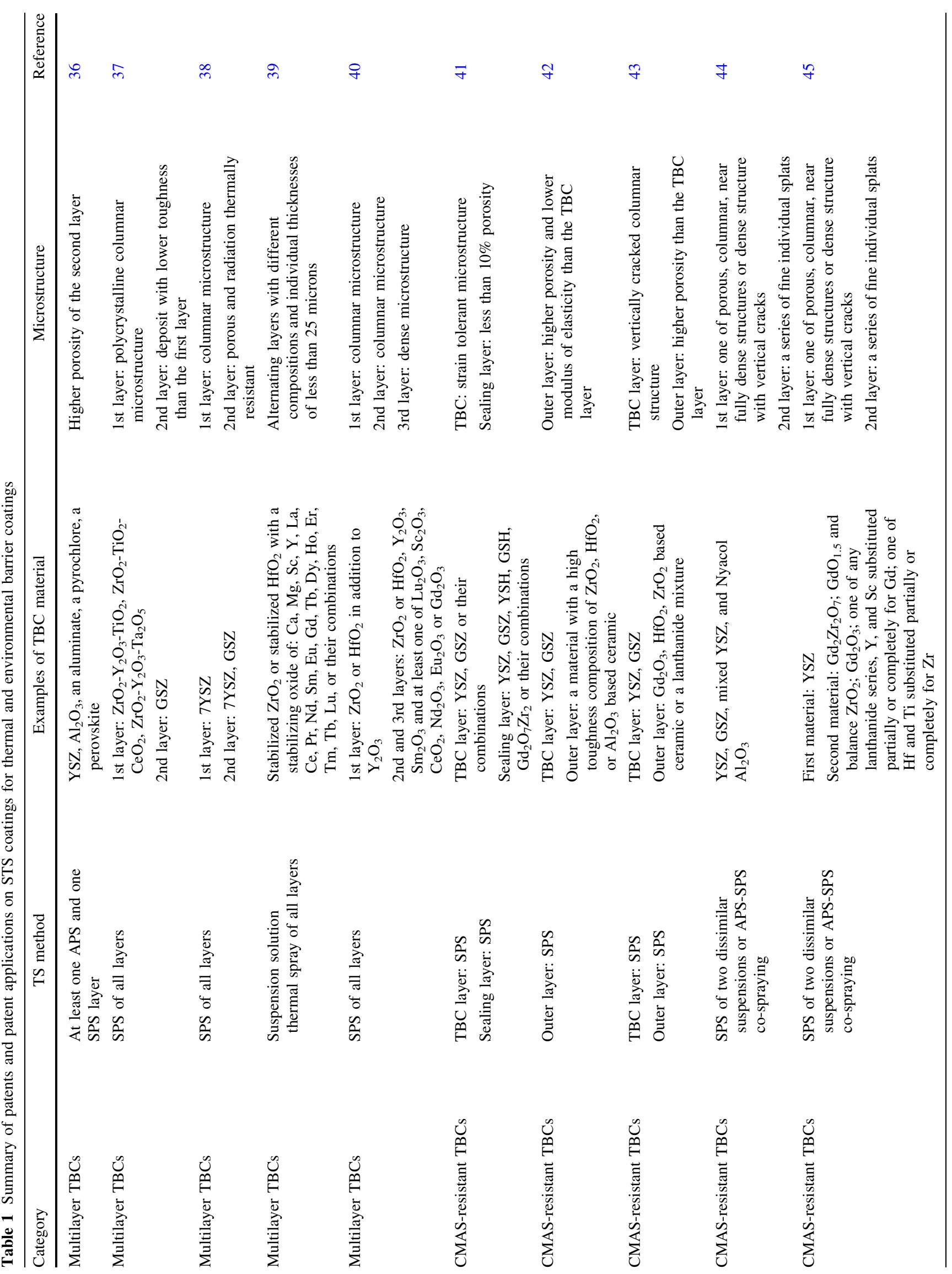




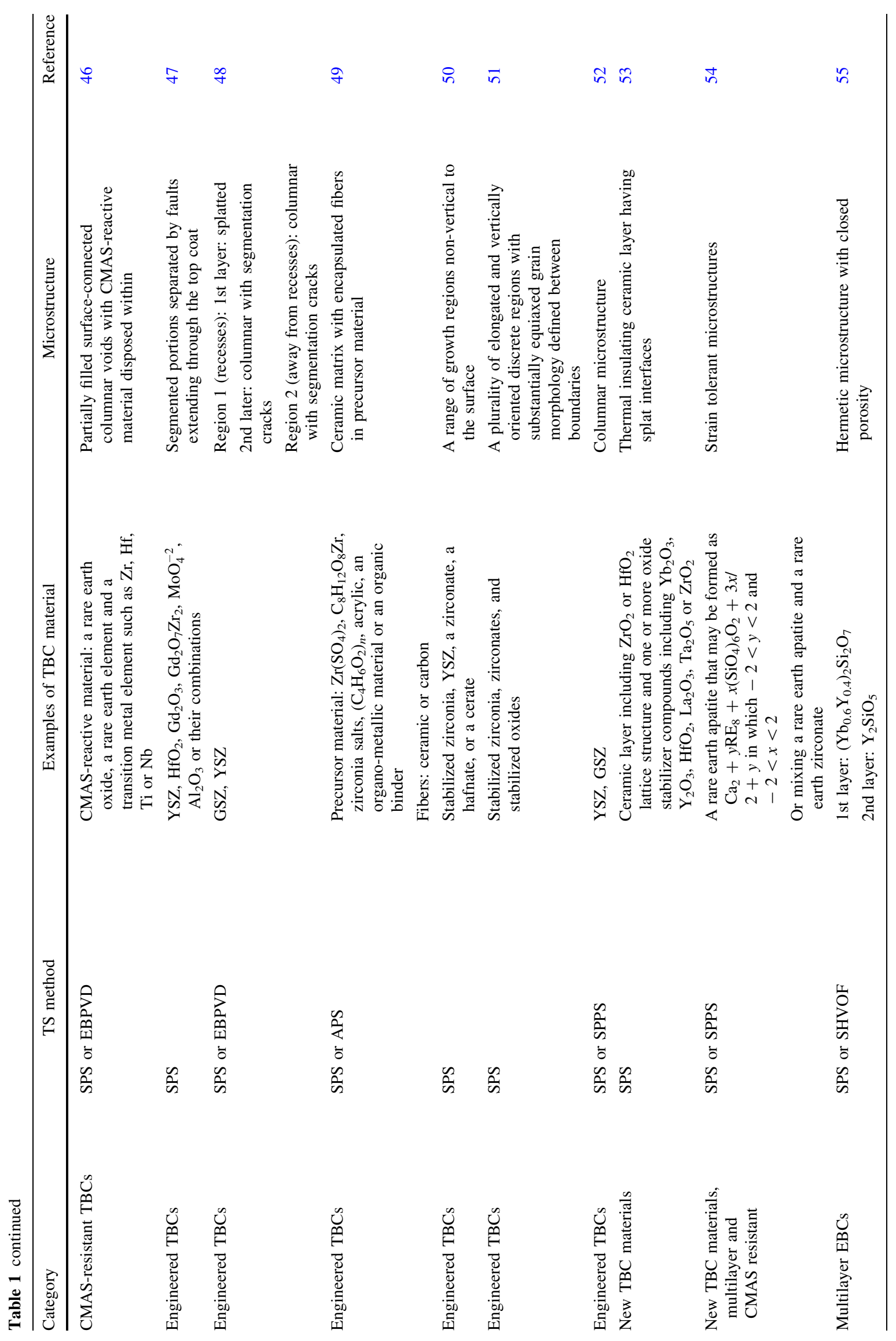




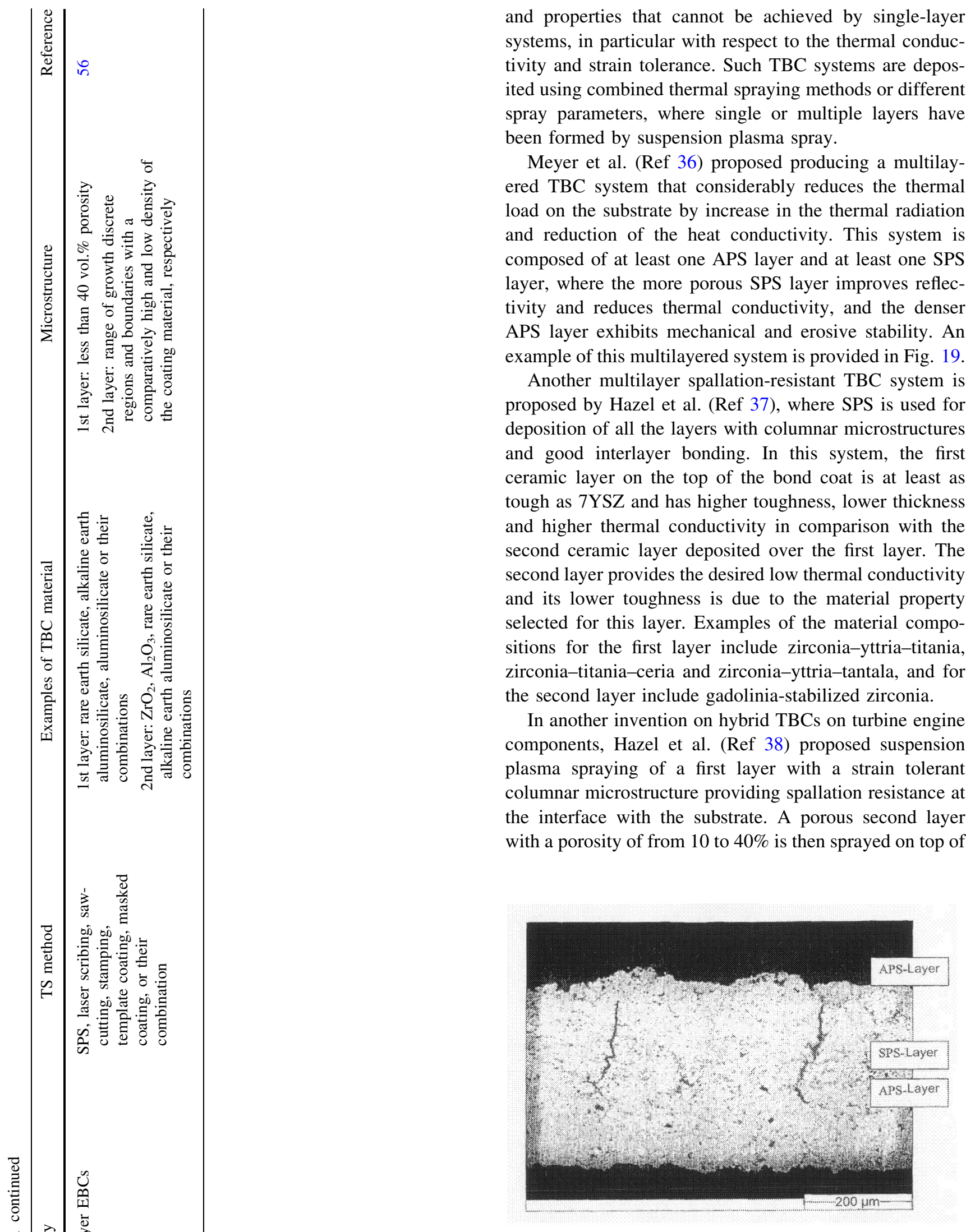

Fig. 19 The cross-sectional microstructure of the triple-layer TBC system (Ref 36) 
the first layer, using similar or a different material from the first layer. Thermal conductivity of the second layer is at least $10 \%$ lower than the first layer, and it provides thermal conduction and radiation thermally resistance.

In a disclosure by Freling et al. (Ref 39) a multilayered coating is formed on the heat shield panel of a combustion chamber. This coating includes alternating layers of different ceramic material compositions that are thermally resistant and are selected from the group of stabilized zirconia and stabilized hafnia with a stabilizing oxide. Each individual layer has a thickness of less than 25 microns. The thin individual layers have different refractive indices due to the different compositions that facilitate thermal radiation scattering to protect the underlying substrate from the relatively high temperatures in the combustor chamber. The multilayered coating is formed by either thermal co-spraying of dry powders, injection of at least one suspension solution into a thermal spray, cospraying of suspension solutions of two different compositions or thermal spraying of a single mixed suspension solution of two different compositions.

Gold et al. (Ref 40) proposed using SPS to deposit multilayered TBC coatings that include at least one layer with a dense microstructure and another layer with a columnar microstructure. The first layer with a columnar microstructure includes predominantly zirconia or hafnia in addition to yttria. The second layer has also a columnar microstructure whereas the third layer is dense with lower porosity than the second layer. The composition of the second and third layers include mainly rare earth oxides such as zirconia or hafnia, yttria, samaria $\left(\mathrm{Sm}_{2} \mathrm{O}_{3}\right)$ and at least one of lutecia $\left(\mathrm{Lu}_{2} \mathrm{O}_{3}\right)$, scandia $\left(\mathrm{Sc}_{2} \mathrm{O}_{3}\right)$, ceria $\left(\mathrm{CeO}_{2}\right)$, neodymia $\left(\mathrm{Nd}_{2} \mathrm{O}_{3}\right)$, europia $\left(\mathrm{Eu}_{2} \mathrm{O}_{3}\right)$, or gadolinia $\left(\mathrm{Gd}_{2} \mathrm{O}_{3}\right)$. SPS is used for deposition of all the TBC layers in order to obtain the selected coating microstructures (dense or columnar). Each layer may provide similar or different properties to provide synergistic properties to the resultant TBC such as improved thermal cycling performance, low thermal conductivity, and improved erosion resistance.

Environmental contaminants such as calcium-magnesium-aluminosilicate (CMAS) limit the operating temperatures of the gas turbine engines due to their detrimental effect on durability of the TBCs. CMAS infiltration in the porous microstructure of the TBCs results in both chemical degradation and microstructural damage leading to spallation of the TBC layer. Therefore, several inventions have focused on CMAS-attack mitigation strategies and development of CMAS-resistant TBCs.

Hazel et al. (Ref 41) improved the CMAS mitigation of the TBC layer by SPS deposition of a sealing layer on top of the TBC, which is also deposited by SPS with a strain tolerant microstructure. The silicate-resistant sealing layer, comprising low porosity of less than $10 \%$, acts as a barrier to CMAS penetration into the thermal barrier layer. The sealing is composed of any yttria-stabilized zirconia, gadolinia-stabilized zirconia, yttria-stabilized hafnia, gadolinia-stabilized hafnia, gadolinium zirconate, or their mixtures.

In a patent application by Strock et al. (Ref 42), it is proposed to deposit an outer layer by SPS that has different porosity and modulus of elasticity compared to the TBC layer. This outer layer is composed of a material that absorbs the impact energy and includes hafnia and/or zirconia-based ceramic material. At an impact event (e.g., by foreign object debris, domestic object debris, or other similar particulate debris) this layer protects the underlying TBC by acting as an impact-resistance energy-absorbing layer or by acting as a sacrificial layer. Figure 20 shows a portion of the outer layer that is deformed in response to an impact during operation of the gas turbine engine.

In another relevant patent application by Strock et al. (Ref 43), it is proposed to select a material for the outer layer that is reactive with the CMAS environmental contaminant, such as a material that includes gadolinia zirconia, hafnia or a lanthanide mixture. The SPS deposited outer layer reacts with the environmental contaminant and forms a solid portion within its porous microstructure, which limits further infiltration of the environmental contaminant into the TBC. This reaction is illustrated in Fig. 21.

Hazel et al. (Ref 44) introduced a hybrid TBC system for which either two dissimilar suspensions are co-sprayed into the plasma simultaneously or in series, a single suspension of dissimilar particulates is sprayed, or a suspension is co-sprayed with at least one dry powder that has a larger particle size. Mixing of dissimilar chemistries and size scales contribute to dual-phase strengthening of the coating. In addition, thermal conductivity of the TBC layer is reduced due to the formation of interlayer boundaries that can act as optical reflection surfaces. In another invention with a similar hybrid TBC system, the first

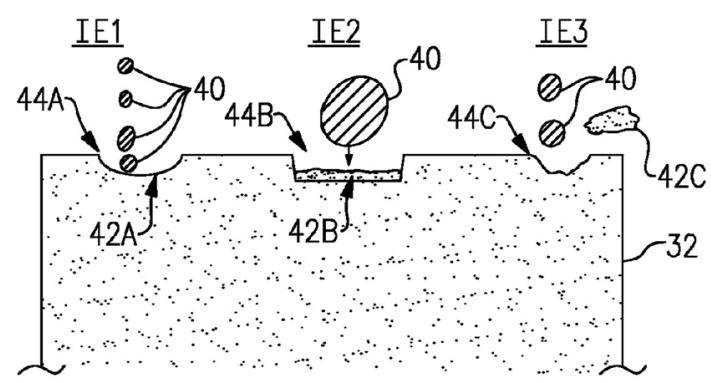

Fig. 20 A portion of an outer layer (\#32) deposited by SPS over a TBC to protect the TBC during an impact event by particulate debris (\#40). The outer layer may absorb the energy of a ballistic strike (\#42A), crushed in response to an impact event (\#42B) or liberated from the outer layer (\#44C) in response to an impact event (Ref 42) 


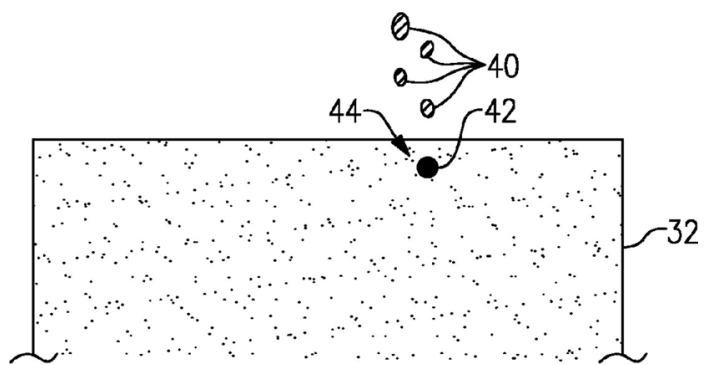

Fig. 21 A portion of the outer layer (\#32) reacts with the environmental contaminant (\#40) and produces an infiltrated or solid portion (\#42) within the porous microstructure formed by SPS (\#44), which prevents further infiltration of the environmental contaminants (Ref 43)

material provides high toughness and it comprises YSZ, whereas the second material is CMAS reactant and it comprises $\mathrm{Gd}_{2} \mathrm{Zr}_{2} \mathrm{O}_{7}$ (Ref 45 ).

In a patent application by Hoel et al. (Ref 46) the TBC layer deposited by EBPVD or SPS includes surface-connected columnar voids partially filled with a CMAS-reactive material. Surface-connected columnar voids are the voids that are open to environmental contaminants at the surface. To obtain the proposed microstructure, a fugitive material such as mineral oil, polyethylene glycol, paraffin wax, or their combinations is first disposed proximate to the substrate within the surface connected columnar voids. Subsequently, a CMAS-reactive material is disposed over the fugitive material. The fugitive material is then removed to form columnar cavities in between the CMAS-reactive material and the substrate to physically separate them. The columnar cavities prevent chemical interaction between the CMAS-reactive material and the thermally grown oxide layer (TGO) formed on the substrate or the bond coat that can cause premature spallation and failure of the TBC. Figure 22 depicts the proposed TBC microstructure.

A number of TBC microstructures have also been engineered to optimize the performance of the TBC layers. An example is a patent filed by Dierberger (Ref 47) on SPS deposition of a thermally insulating top coat on a turbine engine component with two distinct surface regions (Fig. 23). The first surface region has a higher surface roughness compared to the second surface region. The surface roughness serves as the incubation site favorable for deposition of the topcoat. The thermally insulating top coat deposited on top of both regions includes multiple segmented portions separated by faults that are initiated from the second region and extended through the top coat. These faults compensate for thermal expansion of the top coat and facilitate reducing of the internal stresses induced at high surface temperatures. This results in less available energy for cracking and delamination between the top coat and the substrate.

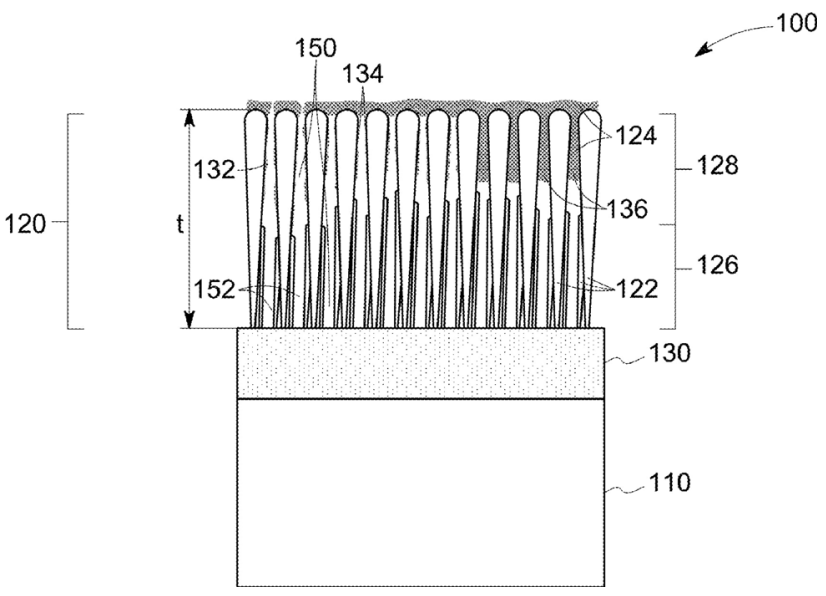

Fig. 22 A schematic view of the TBC layer with partially filled surface-connected columnar voids (\#150) and columnar cavities (\#152) separating the CMAS reactive material (\#124) from the substrate (Ref 46)

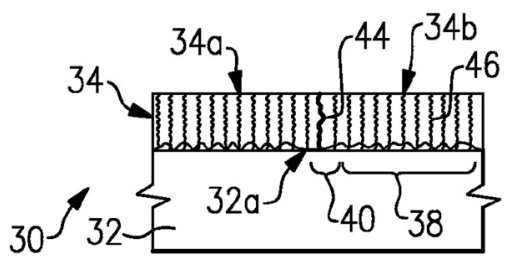

Fig. 23 Portion of a component of a turbine engine component that includes a substrate (\#32) and a thermally insulated top coat (\#34). The surface includes a surface pattern with first surface regions (\#38) and second surface regions (\#40) (Ref 47)

Strock et al. (Ref 48) proposed a slightly different approach in a patent application where the TBC benefits from microstructures that can dissipate stresses caused by sintering shrinkage and/or different thermal expansion coefficients in between dissimilar coating materials. A substrate with two surface regions is used, where the first surface region includes recesses and the second region is in between the recesses. A ceramic coating composed of two layers is then deposited at the recesses: a thick layer with splatted microstructure and a thin layer on its top with a columnar microstructure. A thin ceramic coating with a columnar microstructure is also deposited along the second region via EBPVD or SPS. Segmentation cracks form along the perimeters of the recesses and propagate through the columnar layers. These cracks can accommodate strain from the thermal expansion of the substrate and/or the coating layers. A schematic view of the proposed TBC layer is shown in Fig. 24.

In another disclosure, Strock et al. (Ref 49) proposed manufacturing fiber-reinforced TBCs to provide increased toughness against cracking. The fibers (e.g., ceramic or carbon) are encapsulated with the precursor material, have a higher melting temperature than the encapsulated 
material and are deposited by SPS or APS. Incorporation of fibers, enhances the fracture toughness of the deposited splat boundaries as the fibers bridge the cracks or splat boundaries. As a result, adhesion in between the splats is improved, which indeed increases the erosion resistance of the TBC.

Resenzweig et al. (Ref 50) proposed a method to improve adhesion in between the TBC layer and the bond coat. This method includes deposition of the TBC layer by spraying of the suspension at a spray angle less than 75 degrees to a tangent of the surface. This provides a range of growth regions that are oriented at angles that are not vertical to the surface. The configured microstructure of the deposited TBC not only provides enhanced adhesion but also improved strain tolerance. In one example, the adhesion strength of the TBC layer to the aluminide-based bond

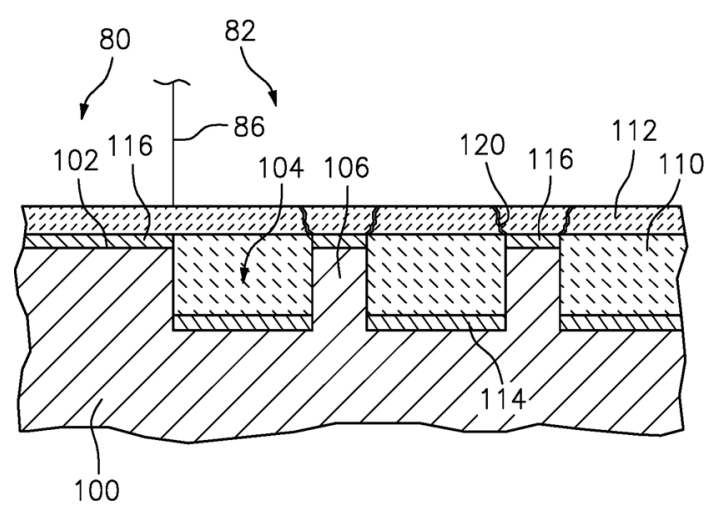

Fig. 24 Schematic view of a coating on an airfoil showing the recesses (\#104), bond coats (\#114 and \#116), splatted ceramic coating (\#110), columnar ceramic coating (\#112) and segmentation cracks (\#120) (Ref 48) coat is higher than $28 \mathrm{MPa}$. Three examples of these type of TBC systems are shown in Fig. 25.

In another invention by Rosenzweig et al. (Ref 51) on SPS deposition of TBCs suitable for use in elevated temperature applications, the TBC is comprised of range of elongated, generally vertically oriented preferential growth discrete regions. The discrete regions have a width of 20-100 microns occupying at least $50 \%$ of the volume, encompass density higher than $75 \%$ of the theoretical density and have substantially equiaxed grain morphology. I addition, a large number of the partially melted and solidified particles is discernible via microscopy of the TBC layer. Presence of longer-well-defined boundaries in between the discrete regions improves the strain tolerance of the coatings, whereas the high density of the discrete regions provides enhanced cohesive strength and higher erosion resistance.

Serra et al. (Ref 52) disclosed a method for applying a TBC system by SPS or SPPS on a platform surface and an airfoil with an end at a platform surface. The ceramic coating is applied by spraying of YSZ and/or GSZ and has a strain tolerant columnar microstructure. Deposition of the coatings by SPS is proposed as it enables deposition on surfaces at off-normal angles or even surfaces that are normal to each other to form desired coatings with uniform thickness maintaining the strain tolerant microstructure. This is normally a challenge with other coating methods such as EBPVD where the surface needs to be oriented toward the evaporating pool.

Selection of the TBC material is another challenge that has been tackled in a number of disclosures on SPS-TBCs. Anand et al. (Ref 53) proposed using a TBC system with ultra-low thermal conductivity and high erosion resistance.
Fig. 25 Micrographs of portions of TBCs deposited at three different pray angles (Ref 50)

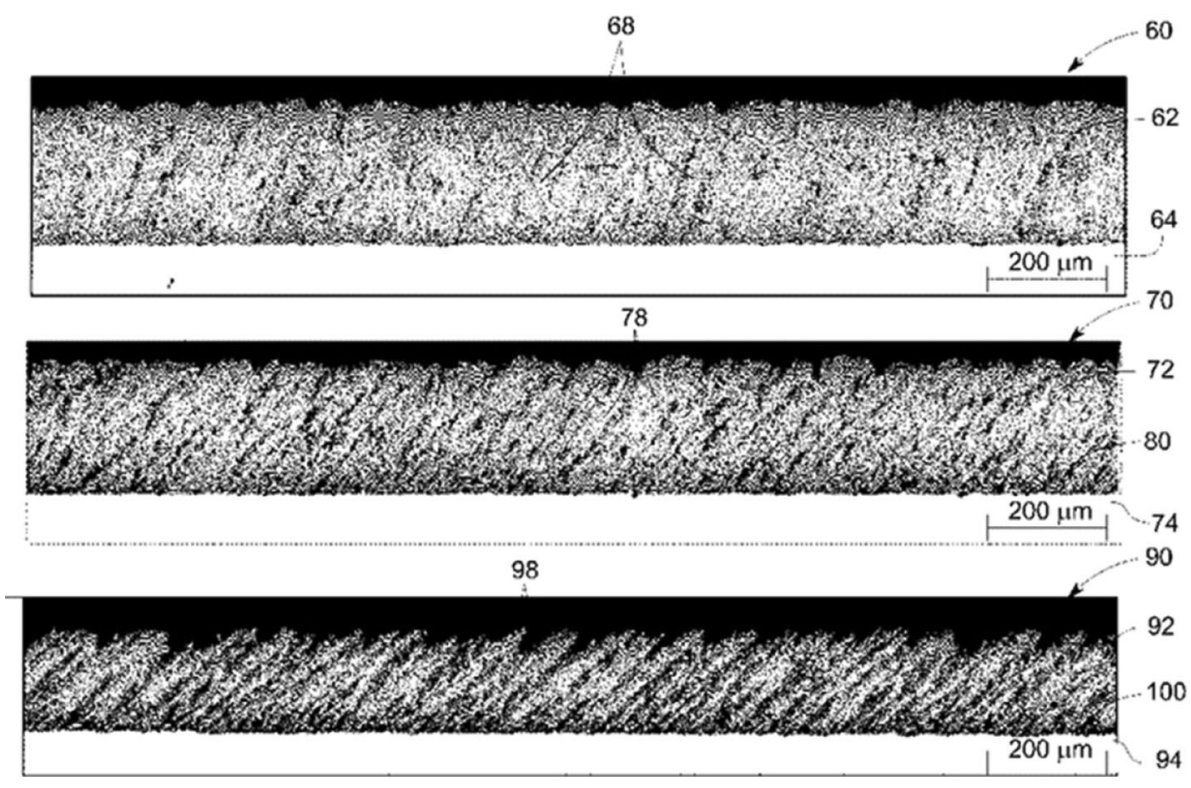


In this system, the top ceramic layer is deposited on an aluminum-rich bond coat or a flash coating by suspension plasma spraying of a zirconium- or hafnium-based oxide lattice structure $\left(\mathrm{ZrO}_{2}\right.$ or $\left.\mathrm{HfO}_{2}\right)$ and one or more oxide stabilizer compounds. The SPS microstructure provides the strain tolerance, while the special pyrochlore structure developed through compositional modifications of the top coat material provides a significant reduction in thermal conductivity.

In attempts to develop TBC materials that react with CMAS to reduce CMAS infiltration, Zaleski et al. (Ref 54) proposed to apply a rare earth apatite, that may be formed as $\mathrm{Ca}_{2}+y \mathrm{RE}_{8}+x\left(\mathrm{SiO}_{4}\right)_{6} \mathrm{O}_{2}+3 x / 2+y$ in which $-2<y<2$ and $-2<x<2$, by SPS or SPPS on the rare earth zirconate TBC material. The apatite can also be applied in the form of a mix with the TBC material to form a graded layer that transits from $100 \%$ rare earth zirconate at the interface with the bond coat to $100 \%$ rare earth apatite at the top surface. Using SPS or SPPS as deposition methods facilitates optimization of the cost and strain tolerance of the TBC by coating of a wide range of chemistries and microstructures.

In a patent filed by Kirby et al. (Ref 55) SPS or SHVOF is proposed to be used for deposition of the EBC layer with a hermetic microstructure. EBC coatings produced by conventional air plasma spray (APS) of rare earth elements are not hermetic due to the porous microstructure in the asdeposited state. Therefore, an additional glassy layer is sprayed to provide a hermetic seal. This glassy layer cannot be directly deposited on the silicon and it requires to be deposited on another layer of rare earth silicate. The proposed SPS or SHVOF sprayed rare earth silicate EBC layer with a hermetic microstructure has a density of at least $85 \%$ of its theoretical density, where hermeticity is achieved by heat treatment of the thermally sprayed layer. Therefore, as shown in Fig. 26, using this method the need of spraying the hermetic glassy layer and the additional rare earth silicate is eliminated. In a disclosure by Wan et al. (Ref 56) an EBC is prepared on a CMC substrate by incorporation of a continuous ceramic inner layer with less than $40 \mathrm{vol} . \%$ porosity and a segmented ceramic outer layer with substantially equiaxed grain morphology. The outer layer is composed of a range of growth discrete regions with a width of 20-100 microns having boundaries in between them and it is generally prepared by SPS or in conjunction with other techniques such as laser scribing, stamping, templated coating, and masked coating. The growth discrete regions and the boundaries include comparatively high and low density of the coating material, respectively. The presence of boundaries in between the discrete regions provides strain tolerance properties for the outer layer. The proposed coating structure improves the lifetime of the component as it is more stable at higher temperatures.

As it was presented (Fig. 5), besides thermal and environmental barrier coatings, there are several other applications where STS is used a part of the invention as listed in Table 2. These patents are further described in the next sections.

\section{Other Protective Coatings}

Hazel et al. (Ref 57) filed a patent on using SPS to deposit strain tolerant abradable coatings on cantilever stators in gas turbine engines. The proposed coating has a columnar microstructure with gaps or cracks that are oriented perpendicular to the surface of the substrate. This microstructure not only provides strain tolerance but it is
Fig. 26 A schematic crosssectional view of an EBC layer (a) in the prior art with the glassy hermetic layer and additional rare earth silicate layer, and (b) with the hermetic thermal sprayed rare earth silicate layer (Ref 55)

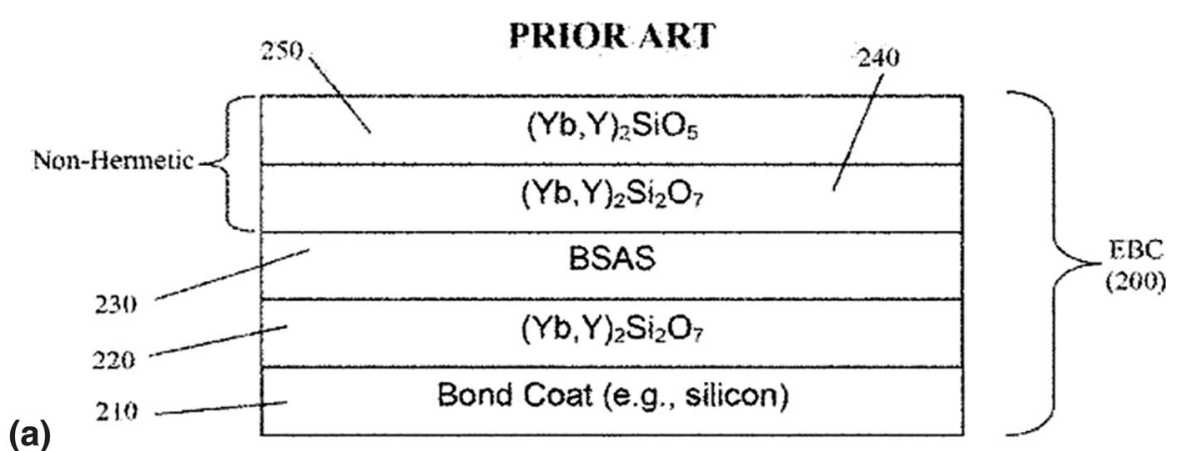

(a)

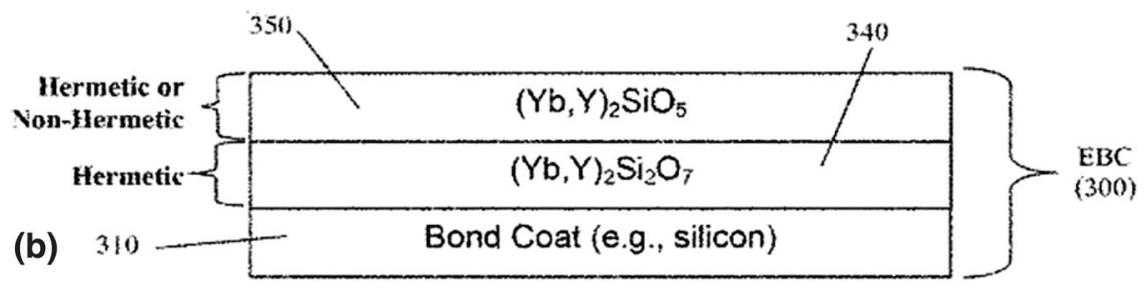




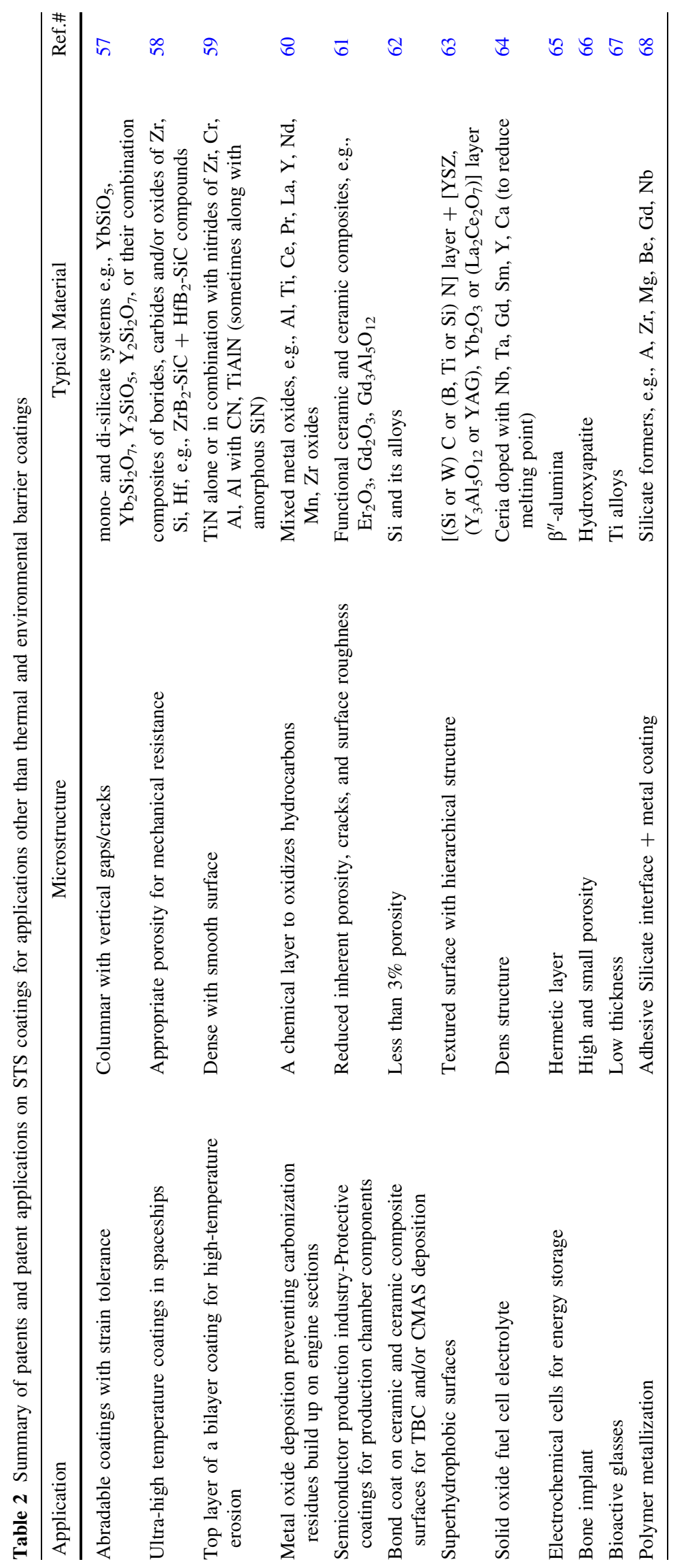


also resilient to crack propagation as the cracks have to jump from one column to the next to cause damage. In contrary, in APS coatings that are typically used for cantilever stators, the cracks form in between the pores and splat boundaries parallel to the surface of the substrate causing delamination by a "crack jumping" mechanism.

Tului et al. (Ref 58) proposed a patent on a suspension thermal spray process for deposition of ultra-high-temperature coatings for aerospace equipment and extreme service conditions encountered on space vehicles. The technique is used under controlled environment of inert gases of $\mathrm{Ar}, \mathrm{He}$ or their mixture in a chamber. The main materials disclosed in this invention are a group of composites based on the borides, carbides and/or oxides of some transition metals such as $\mathrm{Zr}, \mathrm{Si}$, and $\mathrm{Hf}$. Some examples are $\mathrm{ZrB}_{2}-\mathrm{SiC}$ and $\mathrm{HfB}_{2}-\mathrm{SiC}$ compounds which are proper materials for thermal protection of sharp leading edges for the space vehicles, apt to reenter Earth atmosphere from outer space. The very high melting point of these materials (up to $3300 \mathrm{~K}$ ) makes some of them very difficult to attain with most of the fabrication processes. The common practice in the industry prior to this invention includes hot pressing which is known to produce coatings with appropriate porosity and mechanical resistance. It imposes, however, limitations in terms of sizes and costs.

Anand et al. (Ref 59) suggested the application of SPS and/or PVD processes to deposit the top layer of a bilayer coating for high-temperature erosion. The coatings were to protect the surfaces in various types of turbines with a greater focus on steam turbine engines. The layers included a dense and smooth top layer of metal nitride material deposited over the first layer of the nickel-chromium matrix in which metal carbide particles are dispersed. The second layer was either titanium nitride alone or in combination with zirconium nitride, chromium nitride, aluminum nitride, titanium carbonitride, and titaniumaluminum nitride. Deposition of the second layer using the nanoparticles of about $50 \mathrm{~nm}$ size made of metal nitrides dispersed in an amorphous silicon nitride or silicon carbide matrix using SPS process was another way for generation of such erosion-resistant top layers.

A frequent problem in combustion engines is the carbonization residues from unburnt fuel and/or lube oil that are bituminous and, in part, highly complex mixtures of hydrocarbons. In order to prevent hydrocarbon residue build-up in engine, exhaust-gas-system or powertrain components, coatings of mixed metal oxides (e.g., Al, Ti, $\mathrm{Ce}, \mathrm{Pr}, \mathrm{La}, \mathrm{Y}, \mathrm{Nd}, \mathrm{Mn}, \mathrm{Zr}$ ) using suspension plasma spray process was suggested in a patent by Ma et al. (Ref 60). The coating is to prevent the carbonization residues that can accumulate on the intake valves. Such accumulation of residues produces undesired changes in the fluid dynamics or closing behavior of the valves and have very negative effects on other component surfaces of the combustion chamber (e.g., the piston working surfaces).

Another application of SPS was found in semiconductor industry. Plasma etch and plasma clean processes are some of the semiconductor manufacturing processes that can damage the substrate support. The plasma can be highly corrosive to the processing chambers and other surfaces that are exposed to the plasma. The chamber component coatings used for protection of these components are typically generated with plasma spray process. However, these coatings contain inherent porosity, cracks, and rough surface finishes, which undermine their performance. Accordingly, Sun et al. (Ref 61) filed a patent with main focus on application of suspension plasma spray ceramic and composite coatings to protect semiconductor production chamber components from processing conditions (should bear in mind that the method was generalized for all coatings). A large group of functional ceramics was deposited using the SPS process such as $\mathrm{Er}_{2} \mathrm{O}_{3}, \mathrm{Gd}_{2} \mathrm{O}_{3}$, $\mathrm{Gd}_{3} \mathrm{Al}_{5} \mathrm{O}_{12}$, etc.

A patent by Li et al. (Ref 62) proposes using STS for deposition of silicon-based bond coats to reduce exposure of ceramic or CMC (ceramic matrix composite) substrates from detrimental environmental species at high-temperature services. In addition, the STS deposited bond coat promotes adhesion in between the substrate and additional layers over the bond coat. The reduced particle size of the coating material used in the suspension, permits deposition of a coating with relatively low overall porosity of less than 3 vol.\% and reduced pore size leading to improved protective properties and longevity. The thermal spray system used includes a plasma spray or a HVOF gun. The bond coat can be sprayed directly on the surface of the substrate without the need for an initial surface preparation while obtaining sufficient adhesion and produces a surface roughness higher than the surface of the substrate. This leads to reduced overall production cost and time for deposition of the bond coat.

\section{Superhydrophobic/Icephobic}

Leblanc et al. (Ref 63) put forward using the SPS process to produce a textured surface comprising a hierarchical structure applied for hydrophobic and superhydrophobic surfaces. Typically, superhydrophobic surfaces have been created by changing both surface chemistry and surface texturing. Accordingly, in this invention sometimes disposing a second layer comprising a low surface energy material on the textured surface is considered useful.

They used suspensions containing at least $50 \%$ of the particles with diameters less than about $5 \mu \mathrm{m}$. Typical materials for the first layer are carbides of silicon or tungsten; nitrides of boron, titanium and or silicon. 
Examples of such ceramics deposited for this purpose are YSZ, yttrium aluminum garnet. $\left(\mathrm{Y}_{3} \mathrm{~A}_{15} \mathrm{O}_{12}\right.$ or $\left.\mathrm{YAG}\right)$, ytterbium oxide $\left(\mathrm{Yb}_{2} \mathrm{O}_{3}\right)$, lanthanum cerate $\left(\mathrm{La}_{2} \mathrm{Ce}_{2} \mathrm{O}_{7}\right)$, or combinations of them. Such a surface is next over-coated using the same SPS process by a low surface energy material like an inorganic material, a fluorinated material, a polymer, or combinations thereof for lowering the surface energy of the surface causing an improvement of superhydrophobicity.

\section{Energy}

The first disclosure found on energy application is that of Oberste-Berghaus et al. (Ref 64) who presented a patent on application of suspension using HVOF process as a costeffective method for fabrication of ceria-containing electrolytes in solid oxide fuel cells (SOFCs). The ceriumbased powder within 20-200 $\mathrm{nm}$ is suspended in an organic solvent e.g., ethylene glycol, ethanol or their mixture. Using an organic carrier increases the in-flight particle temperatures and accelerates them to higher velocities. Although higher velocities in HVOF process tend to end up with lower temperatures for the in-flight particles, the increased flame temperature as a result of burning of the organic solvent impairs this effect. In addition, using dopants such as an oxide of one or more of the following elements: $\mathrm{Nb}, \mathrm{Ta}, \mathrm{Gd}, \mathrm{Sm}, \mathrm{Y}, \mathrm{Ca}$, and $\mathrm{Sr}$ in the ceria suspensions results in reduced oxide melting point, thus improving the probability of melting of the particles and generating a dense microstructure.

In another patent, Striker et al. (Ref 65) proposed using suspension with either plasma or HVOF to generate electrolyte of beta"-alumina (beta double prime alumina) coating separator (/membrane) over a porous substrate for the application in electrochemical cells used in energy storage devices. The membrane functions as a hermetic layer that would prevent the movement of liquid or gaseous material from one side to the other. The STS process is considered, in the invention, to be also able to form electrolytes for a variety of electrochemical devices. Examples include the sodium metal halide types described in the patent, or sodium sulfur batteries as well as electric converters that employ similar types of electrolytes. One illustrative device is the alkali metal thermal-to-electric converter (AMTEC).

\section{Biomaterials}

Wu et al. (Ref 66) attempted to prepare porous hydroxyapatite coatings (which is of use in implants for biomedical materials) using SPS process. This invention proposes the use a pore-forming agent into the hydroxyapatite suspension whose solid content ranges between 16 and $45 \%$. The pore formers in this invention are considered to be the ethanol and demineralized water carriers, in addition to ammonium carbonate and or ammonium bicarbonate. The idea was to increase the porosity of the hydroxyapatite deposited coatings to help growing the new tissue into the implant surface, thus improving the early fixation and long-term stability of the implants.

The same group also patented the application of suspension and or sol deposition with low-pressure plasma spraying for preparing bioactive glasses (Ref 67). The technique is used to replace sol-gel or other wet chemistry methods where the synthesized coatings generally exhibit low thickness and low production efficiency, thus higher cost. In this invention, the biomedical substrate material is biomedical grades of titanium or its alloys, stainless steel, Co-based alloys or any other biomedical metallic, ceramic, or composite materials. The choices of biocompatible alloys are based on their resistance to high-temperature condition of the used thermal spray process.

\section{Repair}

Application of suspension plasma spray for repair of a damaged TBC surface of a gas turbine engine component was disclosed by Ucasz (Ref 69). The TBC layer is formed by EBPVD, SPS or APS. The repair area is first prepared by removing the damaged TBC down to the bond coat by grit blasting, water jet or laser removal. The TBC ceramic material is then deposited by SPS onto the prepared surface to produce columnar ceramic microstructure substantially similar to the undamaged TBC. Subsequently, the repaired area is leveled flush with the surrounding TBC by sanding.

Boyd (Ref 70) proposed a new repair method for a sintered or plasma sprayed electrostatic chuck using suspension slurry plasma spray. A portion of the repair area of the used electrostatic chuck is first removed to expose the underlying surface and a new layer is then deposited using a suspension slurry of a nano-sized dielectric material composed of aluminum oxide or aluminum nitride. This process is followed by surface roughening and selective removal from the deposited material to form mesas. The refurbished electrostatic chuck is thereafter cleaned and returned to service.

\section{Part Fabrication}

The disclosure by Charbonnelle (Ref 71) may be the first time that the SPS process is used for part production. The invention uses SPS for generating bumps and irregularities on the periphery of the turbine shafts. The bumps are added to a part of the low pressure (LP) shaft body to control the temperature rise in the system. The advantage of using SPS process for this purpose is counted to be controlled porosity by adjusting experimental parameters. This enabled 


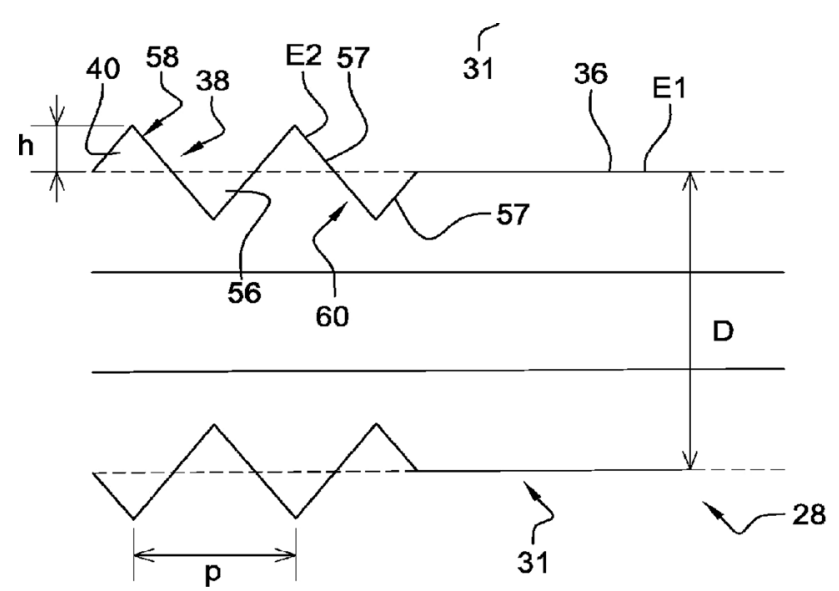

Fig. 27 Typical bumps (\#40) generated using SPS (Ref 71)

deposition of a range of layers having different chemical compositions and porosities using either one or more suspensions, as well as working in the open air with minor modifications to a conventional plasma spraying system. Typical bump shapes and the application of the method are presented using Fig. 27.

Although the bump shapes as shown seem to be simple, it is an interesting departing point toward fabrication of some specific part features where stress concentration due to machining of the sharp corners can cause catastrophic failure.

\section{Metallization of Polymers}

In a patent application by Crawmer et al. (Ref 68), a method for coating fiber-reinforced composite materials by SPS or SPPS is proposed. The proposed substrate is a glass-fiberreinforced polymer and the coating material is one of aluminum, zirconium, magnesium, beryllium, gadolinium, neodymium or other silicate formers and a silicate is formed at the interface between the coating and the glass fibers. Alternatively, the substrate could be a carbon-fiber-reinforced polymer and the coating is one of tungsten, titanium, tantalum, vanadium, zirconium, hafnium, chromium, boron, silicon or other carbide formers and a carbide is formed at the interface in between the coating and the carbon fibers. The surface of the fiber-reinforced composite substrate is treated, for example by laser ablation, to remove the polymer matrix and expose the fibers. SPS or SPPS is used to deposit a coating that is bonded directly to the exposed fibers.

\section{Concluding Remarks}

In this paper, we have highlighted the patents and patent applications pertaining to suspension thermal spray. Three main domains where STS was used exclusively as a part of the invention where identified: (1) Apparatus and methods, (2) Feedstock \& new Material Systems and (3) Applications. Significant efforts were dedicated to the development of new apparatus and hardware systems, as more than one quarter $(28 \%)$ of the reviewed inventions tackled this domain. These new advances aim at the production of more reliable and durable equipment for depositing SPS coatings with improved quality as well as more diverse and bettercontrolled microstructures for utilization in various industrial applications. Optimization of the parameters using the advanced hardware to generate the required properties for each specific application is another critical step.

Regarding the feedstock and new materials, one should note that the development of new suspensions or new ways to prepare suspensions optimized for STS applications has not been the object of numerous patents. Suspension preparation raises new challenges in terms of stability, dispersion, viscosity, etc. for every new material used. This issue can impose some barriers for industrial-scale applications of the STS process as reflected by a low number of patents $(5 \%)$ related to this topic. On the other hand, this shows high potential for further development with the expected growing number of industrial applications of the STS technology in the future.

The largest number of patents reviewed in this paper are related to specific applications in different industrial sectors. During the past decade, a limited number of industries have been extensively working on development of the STS technology for different applications that have reached a sufficient degree of maturity for industrial implementation. With about $40 \%$ of the inventions on the TBCs/EBCs, aerospace is identified as the sector in which STS technology has reached the highest degree of maturity. The rather small number of patents on other applications shows that other industrial sectors have just started the investigation and/or implementation of this technology. However, it is still not clear from this review the extent that STS technology is being actually used in production. From what was presented in this review paper, STS seems to be very promising for most of these new applications and worth further technology development toward the needs of these different industries. A novel and interesting example of utilizing STS as a coating solution is for repair. Noticing the great importance of rapid and economical ways to repair components to enhance their service life and reduce the overhaul time, this is a crucial need for key industries such as aerospace, oil and gas, and energy. Moreover, it is thought that applications where the STS coating technology can be the right solution are numerous and there is a need for a far greater effort on this aspect. Some of the other industrial applications where STS is currently being utilized, to the authors' knowledge, include: parts for the semiconductor industry and gas sensors. 
Although the extent of patents reviewed in this paper is limited to those published in the English language, it was noted that the number of inventions on STS is still very limited while the potential of this technology is certainly not yet fully exploited. Accordingly, more patent applications and actual industrial implementations of the STS technology are expected in the coming years.

Acknowledgments The authors acknowledge the support of Rebecca Jansen, Alain Borsi and Ian Henderson (NRC-NSL) for the bibliographic search.

\section{References}

1. F. Gitzhofer, E. Bouyer, and M.I. Boulos, Suspension Plasma Spray, US5609921A (Universite de Sherbrooke, 1994)

2. J. Karthikeyan, C.C. Berndt, J. Tikkanen, J.Y. Wang, A.H. King, and H. Herman, Preparation of Nanophase Materials by Thermal Spray Processing of Liquid Precursors, Nanostruct. Mater., 1997, 9(1), p 137-140

3. K. Wittmann, F. Blein, J. Fazilleau, J.-F. Coudert, and P. Fauchais, A New Process to Deposit thin Coatings by Injecting Nanoparticles Suspensions in a DC Plasma Jet, in Proceedings of the International Thermal Spray Conference, eds. by C. Berndt, E. Lugsheider (2002), p. 519-522

4. J. Oberste-Berghaus, S. Bouaricha, J.G. Legoux, and C. Moreau, Injection Conditions and In-Flight Particle States in Suspension Plasma Spraying of Alumina and Zirconia Nano-Ceramics, in Proceedings of the International Thermal Spray Conference (2005), p 1-7

5. R. Siegert, J.E. Doring, J.L. Marques, R. Vassen, D. Sebold, and D. Stover, Influence of the Injection Parameters on the Suspension Plasma Spraying Coating Properties, in Proceedings of the International Thermal Spray Conference, DVS (2005), p 1-6

6. E.H. Jordan, L. Xie, C. Ma, M. Gell, N. Padture, B. Cetegen, J. Roth, T.D. Xiao, and P.E.C. Bryant, Superior Thermal Barrier Coatings Using Solution Precursor Plasma Spray, J. Therm. Spray Technol., 2004, 13(1), p 57-65

7. J. Oberste Berghaus, J.-G. Legoux, C. Moreau, F. Tarasi, and T. Chráska, Mechanical and Thermal Transport Properties of Suspension Thermal-Sprayed Alumina-Zirconia Composite Coatings, J. Therm. Spray Technol., 2008, 17(1), p 91-104

8. H. Kassner, R. Siegret, D. Hathiramani, R. Vassen, and D. Stoever, Application of Suspension Plasma Spraying (SPS) for Manufacture of Ceramic Coatings, J. Therm. Spray Technol., 2008, 17(1), p 115-123

9. R.S. Lima, B.M. Guerreiro, and M. Aghasibeig, Microstructural Characterization and Room-Temperature Erosion Behavior of As-Deposited SPS, EB-PVD and APS YSZ-Based TBCs, $J$. Therm. Spray Technol., 2019, 28(1-2), p 223-232

10. A. Killinger, R. Gadow, G. Mauer, A. Guignard, R. Vaßen, and D. Stöver, Review of New Developments in Suspension and Solution Precursor Thermal Spray Processes, J. Therm. Spray Technol., 2011, 20(4), p 677

11. L. Pawlowski, Finely Grained Nanometric and Submicrometric Coatings by Thermal Spraying: A Review, Surf. Coat. Technol., 2008, 202(18), p 4318-4328

12. W. Fan and Y. Bai, Review of Suspension and Solution Precursor Plasma Sprayed Thermal Barrier Coatings, Ceram. Int., 2016, 42(13), p 14299-14312

13. M. Jadidi, S. Moghtadernejad, and A. Dolatabadi, A Comprehensive Review on Fluid Dynamics and Transport of Suspension/
Liquid Droplets and Particles in High-Velocity Oxygen-Fuel (HVOF) Thermal Spray, Coatings, 2015, 5(4), p 576-645

14. P. Fauchais and G. Montavon, Latest Developments in Suspension and Liquid Precursor Thermal Spraying, J. Therm. Spray Technol., 2010, 19(1), p 226-239

15. P. Fauchais, M. Vardelle, A. Vardelle, and S. Goutier, What Do We Know, What are the Current Limitations of Suspension Plasma Spraying?, J. Therm. Spray Technol., 2015, 24(7), p $1120-1129$

16. https://www.questel.com/software/orbit-intelligence/. Accessed 2019/05/6

17. J. Oberste-Berghaus, S. Bouaricha, J.G. Legoux, C. Moreau, and B. Harvey, Method and Apparatus for Fine Particle Liquid Suspension Feed for Thermal Spray System and Coatings Formed Therefrom, US8629371B2 (National Research Council of Canada, 2005)

18. X. Ma, J. Roth, and T.D. Xiao, Methods of Making Finely Structured Thermally Sprayed Coatings, US20080072790A1 (Inframat Corp, 2006)

19. R. Gadow, A. Killinger, M. Kuhn, and D.L. Martinez, Method and Apparatus for Thermal Spraying of Suspensions, DE102005038453B4 (Tti-Technologie-Transfer-Initiative An Der Universitaet Stuttgart GmbH, Tti Technologie Transfer Initiative An Der Uni Stuttgart GmbH, Tti-Technologie-TransferInitiative An Der Universitat Stuttgart GmbH, 2005)

20. A.W. Burgess, P.M. Hartell, C.S.M. Davidson, and Z. Tang, Method and System for Producing Coatings from Liquid Feedstock Using Axial Feed, US20110237421A1 (Northwest Mettech Corp, 2008)

21. E.M. Cotler and R. Molz, Pressure Based Liquid Feed System for Suspension Plasma Spray Coatings, US9089862B2 (Oerlikon Metco (US) Inc, 2011)

22. A. Korolev and Z. Celler, Injector for Plasma Spray Torches, US20130098880A1 (Northwest Mettech Corp, 2011)

23. W.F. Werkheiser, B.T. Hazel, and J.F. Blondin, Suspension Plasma Spray Apparatus and Use Methods, US9669365B2 (United Technologies Corp, 2014)

24. W.F. Werkheiser and B.T. Hazel, Suspension Plasma Injector System and Method of Flushing The System, US9718075B2 (United Technologies Corp, 2014)

25. B.T. Hazel, J.L. Serra, and X. Liu, Suspension Plasma Spray Apparatus and Use Methods, US20170198379A1 (United Technologies Corp, 2016)

26. C.A. Petorak, D.J. Lemen, A. Feuerstein, T.F. Lewis, and M. McCoy, System and Method for Utilization of Shrouded Plasma Spray or Shrouded Liquid Suspension Injection in Suspension Plasma Spray Processes, US20130157040A1 (Praxair S T Technology Inc, 2011)

27. C.A. Petorak, D.J. Lemen, A. Feuerstein, and T.F. Lewis, $R e$ active Gas Shroud or Flame Sheath for Suspension Plasma Spray Processes, US20130156968A1 (Praxair S T Technology Inc, 2011)

28. K. VanEvery, Thermal Spray Method Integrating Selected Removal of Particulates, US20150086725A1 (Progressive Surface Inc, 2012)

29. T.E. Mantkowski, R.W. Heidorn, N.N. Das, and A.W. Reynolds, Process for Depositing a Ceramic Coating and Product Formed Thereof, US10196929B2 (General Electric Co, 2012)

30. M.P. Bochiechio, B.T. Hazel, and J.L. Serra, Systems and Methods for Removing Overspray, US20150197840A1 (United Technologies Corp, 2014)

31. B.T. Hazel, J.A.D. Palma, J.L. Serra, H.H. Thayer, D.R. Blankenship, M.P. Bochiechio, and P.H. Zajchowski, Equipment for Plasma Spray with Liquid Injection, US9752223B2 (United Technologies Corp, 2014) 
32. E. Meillot, R. Vert, J. Toulc'Hoat, G. Mariaux, and A. Vardelle, Method for Preparing a Multilayer Coating on a Substrate Surface by Means of thermal Spraying, US20130101745A1 (Commissariat a 1 Energie Atomique et aux Energies Alternatives Universite de Limoges, 2010)

33. P.R. Strutt, B.H. Kear, and R.F. Boland, Nanostructured Feeds for Thermal Spray Systems, Method of Manufacture, and Coatings Formed Therefrom, US6579573B2 (University of Connecticut Rutgers State University of New Jersey, 1995)

34. E.H. Jordan, M. Gell, and D. Chen, Preparation of Amorphous Mixed Metal Oxides and Their Use as Feedstocks in Thermal Spray Coating, US8679246B2 (University of Connecticut, 2010)

35. B. Callen, J. Liu, M. Nestler, E. Stelmack, and M. Runte, Preformulated Powder Feedstock, US20170121804A1 (Oerlikon Metco (US) Inc, 2014)

36. A. Meyer, H. Kassner, R. Vassen, D. Stoever, and J.L. MarquesLopez, Thermal Barrier Coating System and Method for the Production Thereof, US20110244216A1 (Forschungszentrum Julich GmbH, 2008)

37. B.T. Hazel, B.J. Zimmerman, and D.A. Litton, Spallation-Resistant Thermal Barrier Coating, US20130224453A1 (United Technologies Corp, 2012)

38. B.T. Hazel, D.A. Litton, and M.J. Maloney, Hybrid Thermal Barrier Coating and Process of Making Same, US20180282853A1 (United Technologies Corp, 2013)

39. M. Freling, J.L. Serra, P.H. Zajchowski, C.L. Ostrout, B.T. Hazel, and M.P. Bochiechio, Article Having Multi-layered Coating, US20170176007A1 (United Technologies Corporation, 2014)

40. M.R. Gold, M. Cybulsky, S. Gong, and L. Li, Thermal Barrier Coatings for Components in High-Temperature Mechanical Systems, US20190017177A1 (Rolls-Royce Corp Rolls-Royce North American Technologies Inc, 2017)

41. B.T. Hazel, D.A. Litton, and M.J. Maloney, Hybrid Thermal Barrier Coating, US20130260132A1 (United Technologies Corp, 2012)

42. C.W. Strock, M. Maloney, D.A. Litton, B.J. Zimmerman, and B.T. Hazel, Thermal Barrier Coating Having Outer Layer, US20140220324A1 (United Technologies Corp, 2012)

43. C.W. Strock, M. Maloney, D.A. Litton, B.J. Zimmerman, and B.T. Hazel, Thermal Barrier Coating for Gas Turbine Engine Components, US20140065408A1 (United Technologies Corp, 2012)

44. B.T. Hazel and M.P. Bochiechio, Ceramic Coating Deposition, US20170016104A1 (United Technologies Corp, 2015)

45. B.T. Hazel, Ceramic Coating Deposition, US20180251881A1 (United Technologies Corp, 2017)

46. C.A. Hoel and K.H. Brosnan, Articles for High Temperature Service and Methods for Making, US20180119270A1 (General Electric Co, 2016)

47. J.A. Dierberger, Segmented Thermally Insulating Coating, US9022743B2 (United Technologies Corp, 2011)

48. C.W. Strock and K.W. Schlichting, Hybrid Thermal Barrier Coating, US20180355734A1 (United Technologies Corp, 2017)

49. C.W. Strock, Method of Manufacturing Fiber Reinforced Barrier Coating, US20160273089A1 (United Technologies Corp, 2013)

50. L.S. Rosenzweig, J.A. Ruud, and S. Sivaramakrishnan, Thermal Barrier Coating Systems and Methods of Making and Using the Same, US20170101875A1 (General Electric Co, 2012)

51. L.S. Rosenzweig, J.A. Ruud, L.S. Leblanc, P.M. Thomas, and S.S. Smith, Protective Coating with High Adhesion and Articles Made Therewith, US8586172B2 (General Electric Co, 2008)

52. J.L. Serra and B.T. Hazel, Thermal Barrier Coatings and Methods, US20170152753A1 (United Technologies Corp, 2015)

53. K. Anand, J.A. Ruud, S.S. Pabla, J.L. Margolies, P. Parakala, and L.S. Rosenzweig, Novel Architectures for Ultra Low Thermal Conductivity Thermal Barrier Coatings with Improved Erosion and Impact Properties, US20150233256A1 (General Electric Co, 2013)

54. E.M. Zaleski and M.P. Bochiechio, Calcium Magnesium Aluminosilicate (CMAS) Resistant Thermal Barrier Coating and Coating Process Therefor, US20160186580A1 (United Technologies Corp, 2014)

55. G.H. Kirby, N.E. Antolino, and L.S. Leblanc, Compositions and Methods for Thermal Spraying a Hermetic Rare Earth Environmental Barrier Coating, US9890089B2 (General Electric Co, 2014)

56. J. Wan and L.S. Rosenzweig, Segmented Environmental Barrier Coating Systems and Methods of Forming the Same, US20180305821A1 (General Electric Co, 2017)

57. B.T. Hazel, K.W. Schlichting, and M.J. Maloney, Suspension Plasma Spray Abradable Coating for Cantilever Stator, US20190024510A1 (United Technologies Corp, 2017)

58. M. Tului and T. Valente, Process for the Manufacturing of Ceramic-Matrix Composite Layers, US6761937B2 (Centro Sviluppo Materiali SpA, 2001)

59. K. Anand, T.J. Muth, S. Sampath, P. Bhattacharya, and B. Dasan, Protective Coatings Which Provide Erosion Resistance, and Related Articles and Methods, US20100304181A1 (General Electric Co, 2009)

60. X. Ma, M.L.P. Galligan, C.R. Castellano, W. Koban, M.J. Froning, and K.E. Voss, Methods for Providing High-Surface Area Coatings to Mitigate Hydrocarbon Deposits on Engine and Powertrain Components, US20120258254A1 (BASF Corp, 2011)

61. J. Sun, B.P. Kanungo, Y. Chen, and V. Firouzdor, Slurry Plasma Spray of Plasma Resistant Ceramic Coating, US20150321964A1 (Applied Materials Inc, 2014)

62. L. Li, S. Gong, M.R. Gold, and A. Bolcavage, High Density Bond Coat for Ceramic or Ceramic Matrix Composites, US20180371600A1 (Rolls-Royce Corp Rolls-Royce North American Technologies Inc, 2017)

63. L.S. Leblanc, J.A. Ruud, K.P. Mcevoy, and A.J. Kulkarni, Methods of Coating a Surface and Articles with Coated Surface, US20140178641A1 (General Electric Co, 2012)

64. J. Oberste-Berghaus, J.G. Legoux, C. Moreau, and S. Hui, Process of Making Ceria-Based Electrolyte Coating, US20110003084A1 (National Research Council of Canada, 2008)

65. T.M. Striker, R.L. Hart, M.J. Alinger, and L. Ajdelsztajn, Methods for the Formation of Beta Alumina Electrolytes, and Related Structures and Devices, US20150147621A1 (General Electric Co, 2013)

66. F. Wu, Y. Huang, L. Song, X. Liu, Y. Xiao, J. Feng, and J. Chen, Method for Preparing Porous Hydroxyapatite Coatings by Suspension Plasma Spraying, US8877283B2 (Si Chuan University, 2009)

67. F. Wu, Y. Xiao, L. Song, X. Liu, Y. Huang, T. Huang, and J. Feng, Method for Preparation of Bioactive Glass Coatings by Liquid Precursor Thermal Spray, US8852667B2 (Si Chuan University, 2009)

68. D.E. Crawmer, I.P. Downs, J.M. Watts, and R. Meuer, Method of Thermal Spray Coating Fiber-Reinforced Composite Materials, WO2018200053A1 (Fisher-Barton Inc., 2017)

69. M.T. Ucasz, Thermal Barrier Coating Repair, US20160281204A1 (United Technologies Corp, 2013)

70. W.G. Boyd, New Repair Method for Electrostatic Chuck, US20180166311A1 (Applied Materials Inc, 2016)

71. P.Y.F. Charbonnelle, Turbine Engine Rotor Shaft Comprising an Improved Heat Exchange Surface, US20160146045A1 (Safran Aircraft Engines SAS, 2014)

Publisher's Note Springer Nature remains neutral with regard to jurisdictional claims in published maps and institutional affiliations. 